\section{REPUBLIC OF AFGHANISTAN}

Assistance to Member States for the development of national documentation, library and archives infrastructures

\title{
Library Development (NATIS)
}

\author{
by John J. Eyre
}
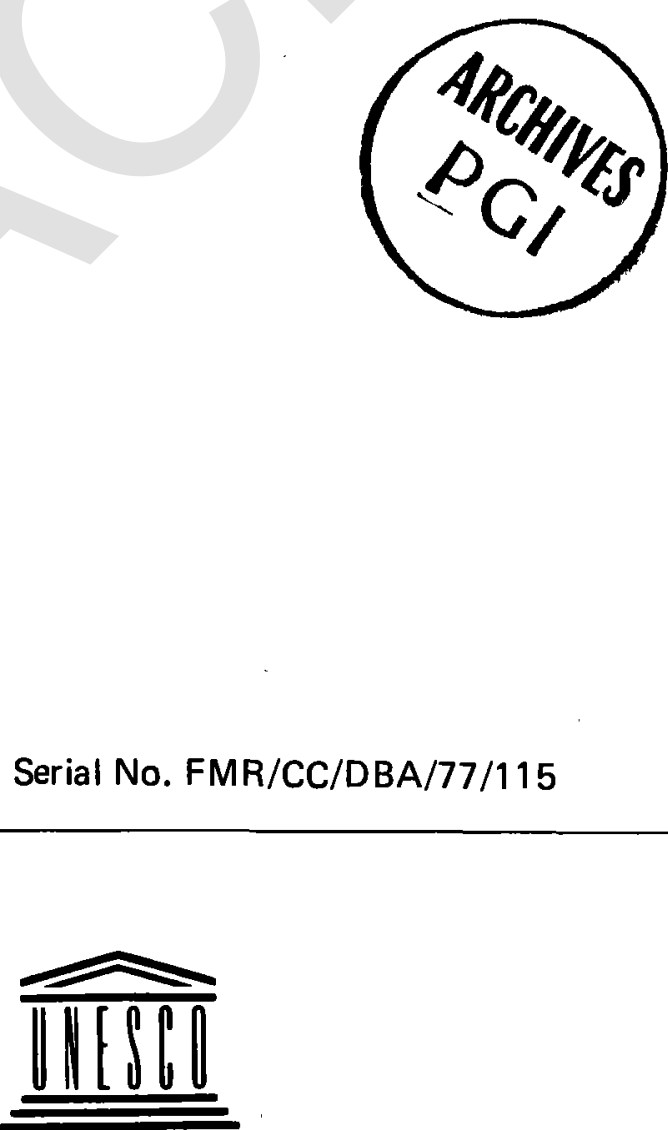

Paris, 1977 
REPUBLIC OF AFGHANISTAN

LIERARY DEVELOPMENT

( N A T I )

by John J. Eyre

Report prepared for the Government of the Republic of Afghanistan by the United Nations Educational, Scientific and Cultural Organization (Unesco)

U N E S C 0 
Technical Report

PP/1975-76/4.221.4

FMR/CC/DBA/77/115 (Eyre)

1 March 1977

Unesco 1977

Printed in France 
INTRODUCTION

A. Objectives and scope of the report.................. T

B. Methodology .................................. 7

C. Availability of statistics........................ 7

D. Population................................. 7

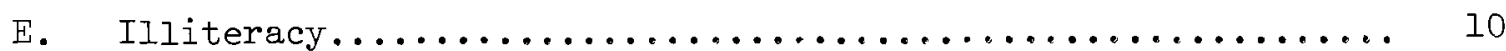

F. Standard of library service..................... 10

G. Lectures and discussions......................... 10

H. United Nations Development Programme Headquarters .......... II

I. Acknowledgements............................. 11

1. PUBLIC LIBRARY SERVICE

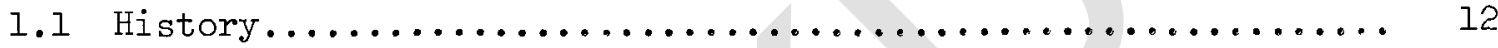

1.2 Services................................. 12

1.3 Buildings.................................. 12

(a) Design of the new central library.................. 13

(b) Design of branch libraries..................... 14

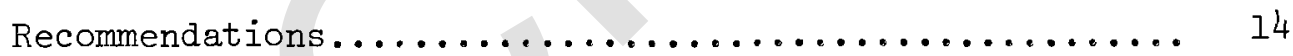

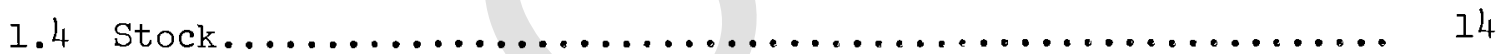

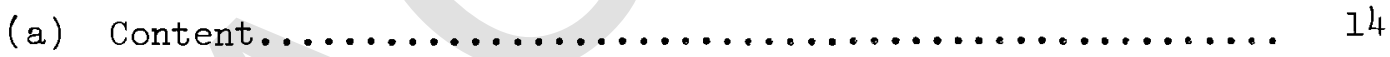

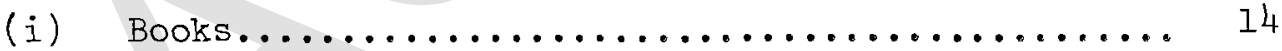

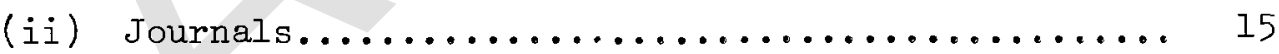

(b) Acquisitions............................ 16

(c) Cataloguing............................ 16

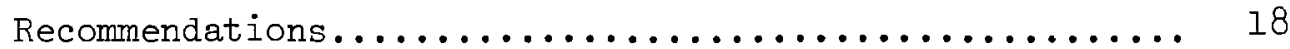

1.5 Provision...................................... 19

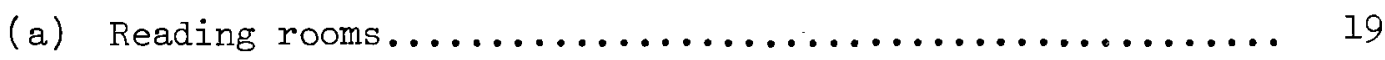

(b) Loans (circulation) .......................... 19

(c) Facilities.............................. 20

Recommendations......................... 21

1.6 Management.................................. 22

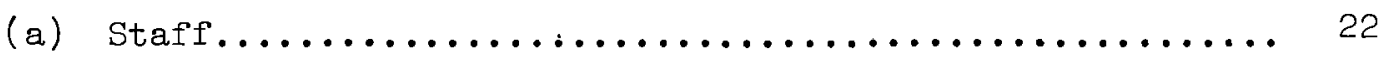

(b) Administration............................ 22

(c) Finance............................... 23

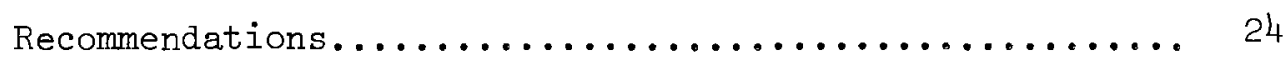


2. NATIONAL LIBRARIES. . . . . . . . . . . . . . . . . . . . . 25

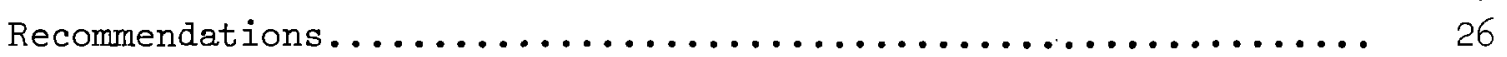

3. UNIVERSITY LIBRARIES

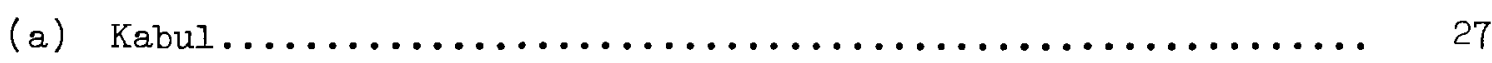

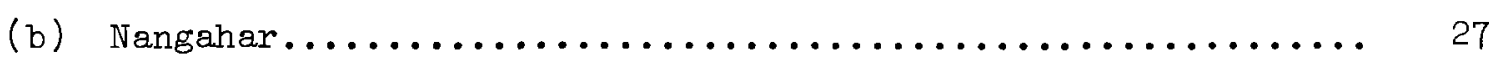

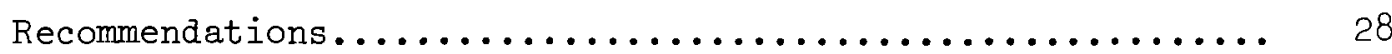

4. TEACHER -TRAINING COLLEGES.......................... 29

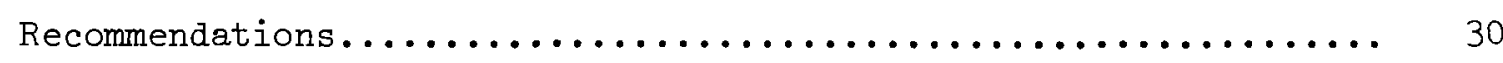

5. SCHOOL LIBRARIES

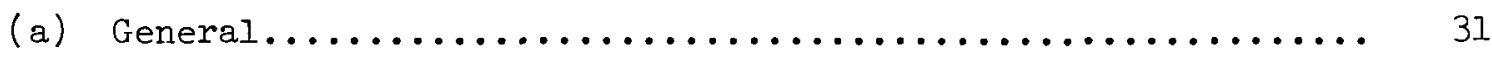

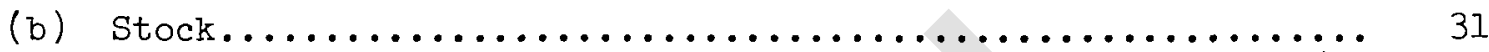

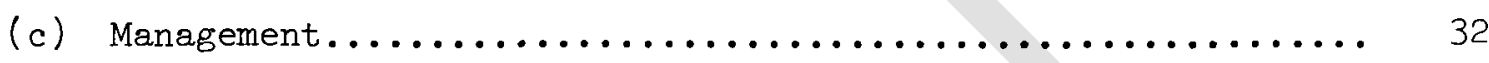

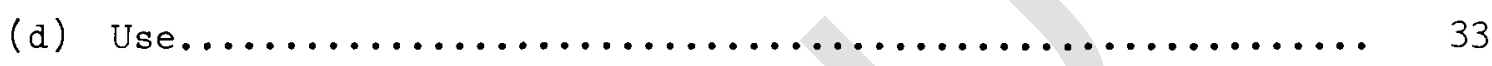

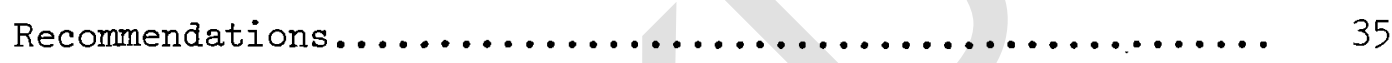

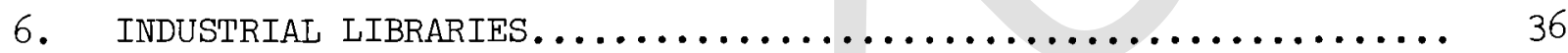

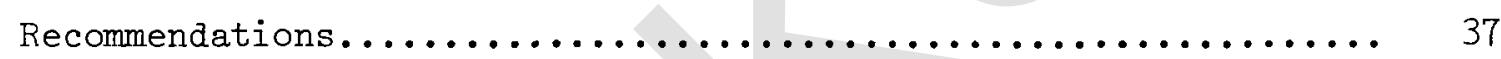

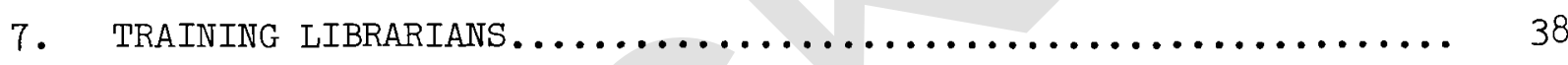

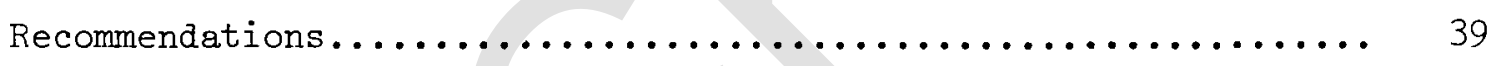

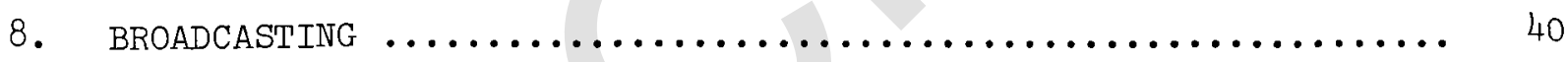

Recommendations..$\ldots \ldots \ldots \ldots \ldots \ldots \ldots \ldots \ldots \ldots \ldots \ldots \ldots \ldots \ldots$

9. PUBLISHING AND BOOKSELLING

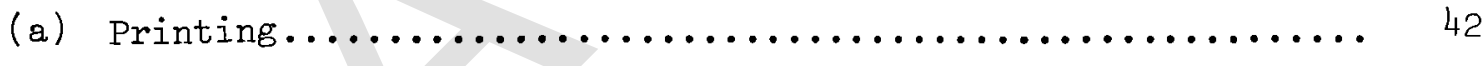

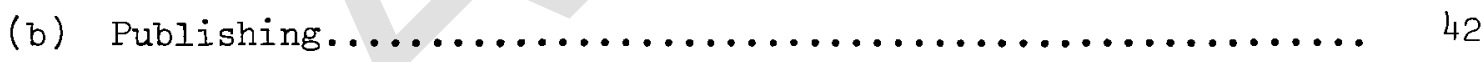

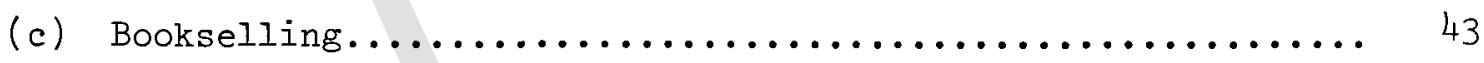

10. COMPUTING FACILITIES

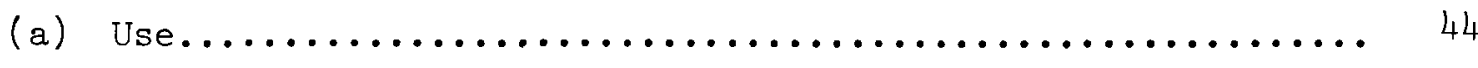

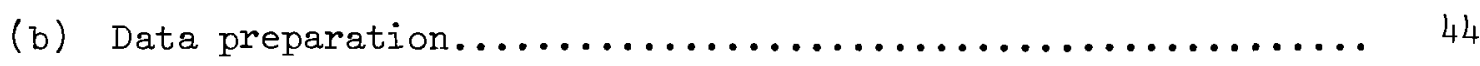

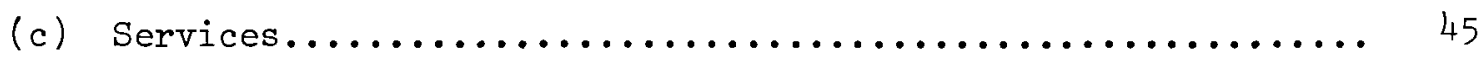

11. INFORMATION SYSTEMS............................ 46

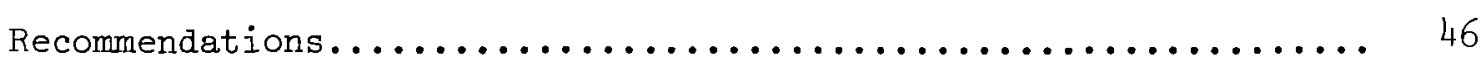

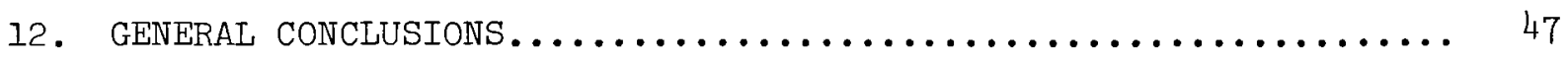

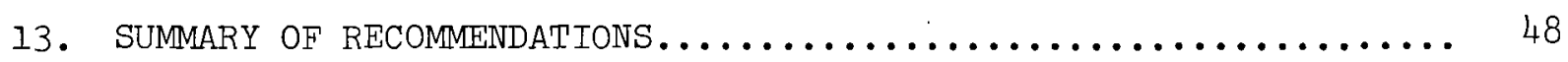




\section{APPENDICES}

1. Political map of Afghanistan

2. Details of branch library designs

3. Details of photographic equipment at the National Archives Library

4. References

5. Schedule of talks and visits

6. List of people visited 


\section{INTRODUCTION}

\section{A. Objectives and scope of the report}

1. At the request of the Republic of Afghanistan, the consultant carried out a mission to that country from $4 \mathrm{July}$ to 3 August 1976, with the following terms of reference:

1. evaluate the present situation of libraries in the country with special reference to the public library service;

2. prepare a plan for public library development in the framework of a National Information System (NATIS);

3. study the feasibility of using computers for library operations;

4. study the training requirements of library personnel;

5. investigate the state of publishing and bookselling.

\section{B. Methodology}

2. Visits were paid to public libraries, the university, the polytechnic, Radio

Afghanistan, the Government Printing Press, ministries, industries, booksellers, schools and the computer centre. A list of the establishments and people visited is given in Appendix 5.

Besides the many officials, professionals and other nationals, many United Nations experts and others were consulted about aspects of their work which seemed relevant to this mission.

\section{Availability of statistics}

3. It was a matter of considerable concern that there seemed to be no reliable statistics from which to make estimates concerning library use. Some tables have been used from the Afghanistan Republic Annual 1974 and 1975 and the Statistical Pocket Book issued by the Ministry of Planning in 1972.

4. Although some statistics are available for the public library service, there is no tradition of producing collated figures annually. Data provided, therefore, can only be regarded as indicating trends in a very general way. Some data were obtained from consultants in United Nations missions engaged in such areas as education, agriculture, telecommunications and broadcasting.

\section{Population}

5. A vital aspect of forecasts for library service requirement relates to the growth and distribution of the population. There seemed to be little correlation between the figures from one source and another. The census project now in train will produce more acceptable figures. In order to indicate roughly the minimum level of demand on the library service, the lowest unofficial estimate for the population - Ilm. - can be used. Official estimates suggest a population of the order of $17 \mathrm{~m}$. people with an annual increase of between eight to ten per cent. A summary of the last official estimates published in 1972 is given below. 
Figure 1

AREA AND ESTIMATED POPULATION

OF AFGHANISTAN IN 1970

\begin{tabular}{|c|c|c|c|c|c|}
\hline Province & $\begin{array}{l}\text { Area in } \\
1000 \\
\mathrm{Sq} . \mathrm{Km} \text {. }\end{array}$ & $\begin{array}{l}\text { Population } \\
\text { in } 1000\end{array}$ & $\begin{array}{l}\text { Density of } \\
\text { Populaticn } \\
\text { per Sq. Km. }\end{array}$ & $\begin{array}{c}\text { Provirsial } \\
\text { Capital }\end{array}$ & $\begin{array}{l}\text { Population } \\
\text { of Capital } \\
\text { in } 1000\end{array}$ \\
\hline $\begin{array}{l}\text { 1. Jruzgan } \\
\text { 2. Jadghis } \\
\text { 3. Bamian } \\
\text { 4. Badakshan } \\
\text { 5. Bagilan } \\
\text { 6. Baikh } \\
\text { 7. Parwan } \\
\text { 8. Paktis } \\
\text { 9. Takhar } \\
\text { 10. Jozjan } \\
\text { 11. Zabul } \\
\text { 12. Samangan } \\
\text { 13. Ghazmi } \\
\text { 14. Ghour } \\
\text { 15. Fariab } \\
\text { 16. Farah } \\
\text { 17. Kunduz } \\
\text { 18. Kandahar } \\
\text { 19. Kabul } \\
\text { 20. Kapisa * } \\
\text { 21. Kunarha * } \\
\text { 22. Laghman } \\
\text { 23. Logar } \\
\text { 24. Nangahar } \\
\text { 25. Nimroze } \\
\text { 26. Wardaik } \\
\text { 27. Eerat } \\
\text { 28. Eelmand } \\
\text { Kuchies }\end{array}$ & $\begin{array}{r}34.0(8) \\
24.7(11) \\
19.2(14) \\
42.6(5) \\
18.6(15) \\
15.1(18) \\
5.6(26) \\
17.6(16) \\
11.8(19) \\
24.7(10) \\
20.0(13) \\
16.0(17) \\
31.4(9) \\
35.1(7) \\
22.9(12) \\
57.8(2) \\
7.4(24) \\
45.1(4) \\
4.5(28) \\
5.8(25) \\
10.3(20) \\
9.1(22) \\
4.5(27) \\
7.6(23) \\
50.0(3) \\
10.3(21) \\
41.5(6) \\
59.7(1) \\
-2(-)\end{array}$ & $\begin{array}{r}513.1(9) \\
329.5(22) \\
356.2(17) \\
354.6(19) \\
641.8(8) \\
364.1(16) \\
913.3(3) \\
859.1(4) \\
508.8(10) \\
442.1(12) \\
368.6(15) \\
213.4(27) \\
1136.4(2) \\
333.0(21) \\
447.5(11) \\
323.5(24) \\
417.4(14) \\
763.1(6) \\
1330.1(1) \\
354.9(18) \\
339.3(20) \\
229.1(26) \\
318.3(25) \\
842.1(5) \\
125.4(28) \\
427.9(13) \\
706.1(7) \\
325.8(23) \\
2801.8(-)\end{array}$ & $\begin{array}{r}15.1(21) \\
13.3(22) \\
18.5(10) \\
8.3(25) \\
34.5(11) \\
24.1(14) \\
163.0(2) \\
48.8(7) \\
43.1(8) \\
17.9(18) \\
18.4(17) \\
13.3(23) \\
36.1(10) \\
9.5(24) \\
19.5(15) \\
5.6(26) \\
56.4(6) \\
16.9(20) \\
295.7(1) \\
78.4(4) \\
32.9(12) \\
25.2(13) \\
70.7(5) \\
110.8(3) \\
2.5(28) \\
41.5(9) \\
17.0(19) \\
5.5(27) \\
-(-)\end{array}$ & $\begin{array}{l}\text { Tareenkoot } \\
\text { Gala-i-nau. } \\
\text { Bamian } \\
\text { Faizabad } \\
\text { Baghlan } \\
\text { Mazarisharif } \\
\text { Charikar } \\
\text { Gardi z } \\
\text { Taluern } \\
\text { Sheberchan } \\
\text { Qalet } \\
\text { Jiback } \\
\text { Ghazni } \\
\text { Cheghcheran } \\
\text { Maimana } \\
\text { Farah } \\
\text { Kunduz } \\
\text { Kandahar } \\
\text { Kabul } \\
\text { Mahmoodraqi } \\
\text { Asadabad } \\
\text { Meterlam } \\
\text { Pulialam } \\
\text { Jelalabad } \\
\text { Zarunj } \\
\text { Maidan } \\
\text { Eerat } \\
\text { Bost } \\
\text { - }\end{array}$ & $\begin{array}{r}48.2(18) \\
78.4(3) \\
46.2(19) \\
64.7(11) \\
103.6(3) \\
44.5(27) \\
93.8(4) \\
40.3(22) \\
68.6(10) \\
55.5(14) \\
51.2(16) \\
39.5(23) \\
44.7(20) \\
62.7(12) \\
57.1(13) \\
29.6(24) \\
82.5(5) \\
130.8(2) \\
513.0(1) \\
72.7(9) \\
28.9(26) \\
74.7(7) \\
27.5(27) \\
50.4(17) \\
17.4(28) \\
55.9(15) \\
73.7(3) \\
29.2(25) \\
-(-)\end{array}$ \\
\hline Afghanistan & $052.9(-)$ & $1 / 1000.3(-)$ & $20.0(-)$ & Kabul & $513.0(-)$ \\
\hline
\end{tabular}

Notes: The figures in parentheses indicate the rank of the province by population and area.

* Since 1973 these provinces have been merged with others. 
6. Although there is not much numerical correlation between them, the map below, which was published in 1974 , does show a proportionate distribution of the population similar to that of the previous table.

\section{Figure 2}

\section{AFGHANISTAN - POPULATION DISTRIBUTION}

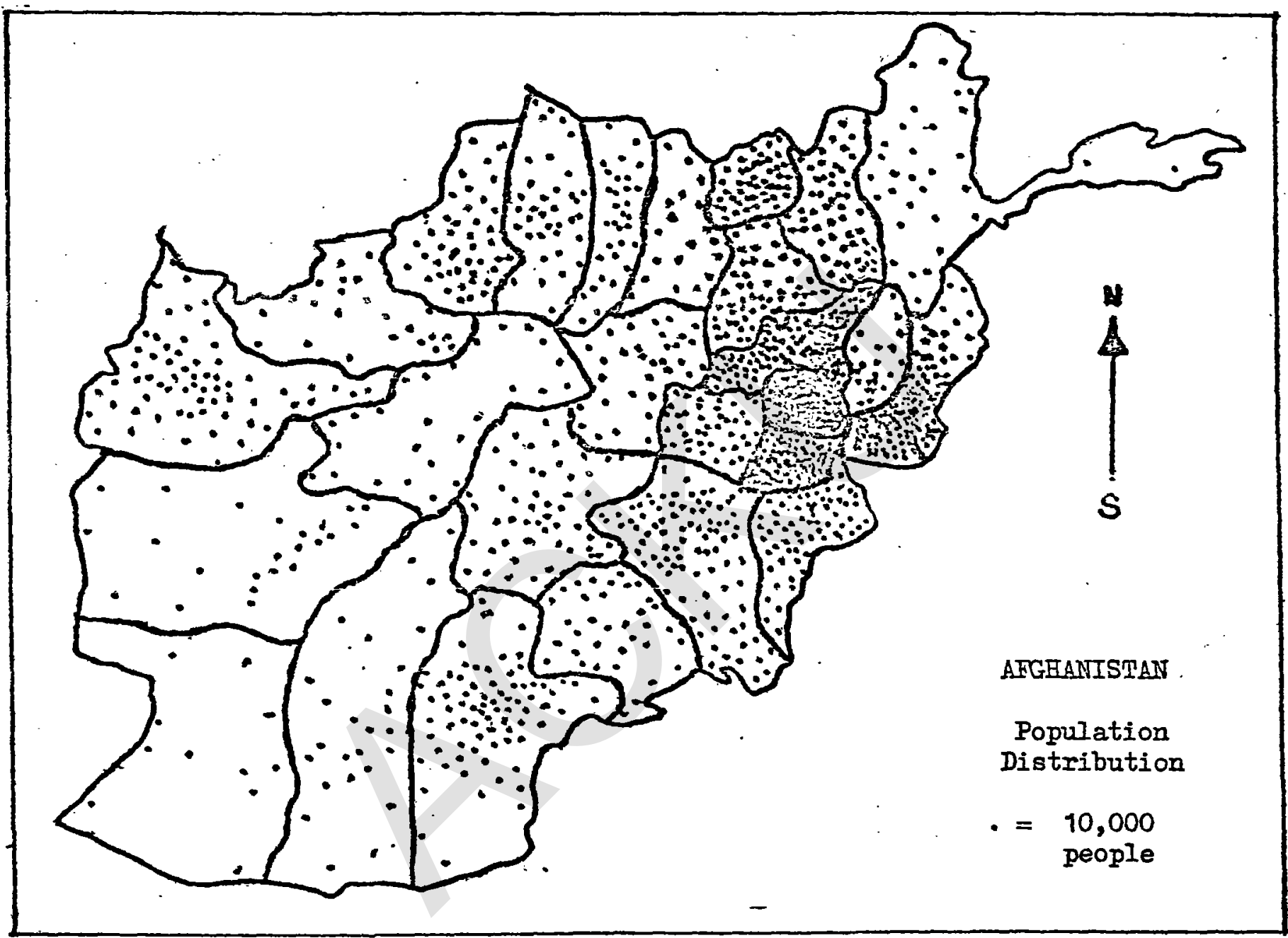

Taken from - The Afghanistan Republic Annual, 1974

7. As can be seen from Figures 1 and 2, considerable population concentration occurs in eastern provinces, particularly Kabul, Parwan, Logar and Nangahar. This density and the willingness of the people to travel journeys lasting two or three hours to reach libraries, has important implications for the future pattern of library service in this area of the country. Verbal reports from United Nations and other personnel suggest that this pattern of population distribution is unlikely to change much during the next decade or two. 


\section{E. IIIiteracy}

8. A vigorous educational programe is being pursued to combat the illiteracy

which has been estimated to be as high as 95 per cent of the population. Compulsory attendance at school, increasing output of trained teachers, an expanding school building programme, regular educational broadcasting and the planned introduction of television, all testify to the efforts being made by the authorities to spread literacy. The task is made more difficult because three languages prevail in the country, Pashto, Dari and Farsi.

9. Unfortunately the campaign against illiteracy needs more co-ordination and, equally importantly, more textbooks and library facilities. Since the provision of education and possible library services is the responsibility of separate ministries, the requisite coherent policy to make the most of the scarce financial resources, trained personnel and literature is rather difficult to formulate.

\section{F. Standard of library service}

10. Generally speaking, although the libraries visited during this mission displayed considerable disparity as to stock, staff, management and use, there is on the whole room for considerable improvement. Except for the few libraries which had received large donations of books from the Asia Foundation or the British Council, and the Kabul University, all libraries had very inadequate stocks. This was due mostly to the paucity of books published in the area, and the smallness of the funds available for purchasing books. The need for works on all subjects in the three main languages is acute and unlikely to be satisfied for some years to come. To cover these subject deficiencies, books published in Western countries are needed. Unfortunately, these are relatively expensive and funds for this purpose are very limited. Even when such works are obtained, students obviously have difficulty with the languages involved. Such a situation points to the need for considerable effort in the production of original and translated works.

11. Other principal problems include the scarcity of properly trained staff and inadequate accommodation.

12. As can be seen from statements in the following sections on the library service, users comprise largely high school students. The libraries therefore tend to emphasize their service to this group through provision of study facilities and a reference stock.

\section{G. Lectures and discussions}

13. By agreement with the President of the public library service, four lectures were given on the following subjects: The rôle of the librarian; Indexing; Management applied to libraries; The librarian as a professional. Each session lasted two hours and was attended by a group of librarians invited from both the public service and other libraries in the capital. Some discussions arose from matters dealt with in the lectures. The texts of these lectures were translated, and copies distributed to all those attending (about 40 people).

14. Discussions on problems facing librarians in the country generally, were held with small groups of invited librarians. Such exchanges helped to assess the difficulties and gave an opportunity to provide suggestions and clarification. 


\section{H. United Nations Development Programme Headquarters}

15. Because the UNDP Headquarters wished to reorganize their reports collection, so as to exploit it more efficiently, I was asked to advise on appropriate methods. Besides discussions on site with the person responsible for the collection, an assistant to carry out the work was found and briefed as to objectives and methodology.

\section{Acknowledgements}

16. Inevitably the contents of this report owe much to the willingness, patience and generous giving of their time of many people both nationals, United Nations staff and others. Especial thanks are due to my counterpart Mr. M.A. Nayyer, Director of the Manuscripts Library, who undertook the main load as interpreter and guide; Mr. A.G. Koschann, Deputy Director-General of the Public Libraries, who efficiently arranged the programme of visits and necessary transport. A particular debt of gratitude is also due to Mr. M.O. Seddiqi, President of the Public Libraries, who spent a generous amount of his time providing current and background information about the libraries of Afghanistan and accompanied me on many visits. It is to be hoped that the contents of this report do justice to the spirit and aspirations of librarians in the country, and afford some assistance in realizing their goals. 


\subsection{History}

17. The present public library service can be said to have started in 1957 under the Ministry of Education as recommended by Mr. H.V. Bonny, a Unesco expert. After the establishment of the Republic in 1973, the public libraries were transferred to the Ministry of Information and Culture. The library is one of the 20 "presidencies" under this Ministry. Responsibility for these is divided at the Ministry between the President of Information and the President of Culture. Particular responsibility for the public library service together with ll other presidencies, including museums, cinemas, theatres, lies with the President of culture. The earliest public library was set up in Kabul in 1921. Since then growth has been steady. There are now four libraries in Kabul and 32 in the provinces. The total bookstock is estimated at 168,000 volumes, 45 per cent of which are in Kabul libraries. Provincial branch stocks vary considerably in size, ranging from 8,200, in Herat to 520 in Farah.

18. The head of the library service (who is also designated a president) is fully responsible for the day-to-day running of the service, whilst the President of Culture retains control over expenditure and general policy. Close liaison is maintained within the Ministry at a weekly meeting of the committee of presidents.

\subsection{Services}

19. The public library service at Kabul runs four libraries in the city. The central, used mostly by high school students, contains three reading rooms, one with reference material, one with general works and one devoted specially to material on Afghanistan. There is also a closed access loan collection and a periodicals section. The central is open from 8 a.m. until 7.30 p.m. every day. In 1976, due to the increasing number of students waiting to use the library reading rooms for study, another building in the park opposite the central library has been requisitioned. This provides seats for some 50 students, and has a stock of some 6,000 books and journals. In another part of the city is a youth club containing a small children's library. The club, which is run entirely by the public library service, offers films, talks, games and gymnastics between 8 a.m. and 4 p.m. each day except Friday and holidays.

20. At the moment the public library is also responsible for the manuscripts and archives libraries which are housed in one large room in the building of the Ministry of Information and Culture. There are an estimated 2,000 rare books and I,000 archive papers in the collection which is to be moved to a specially converted building (for fuller information see the section in this report on "National Libraries").

\subsection{Buildings}

21. The present central library building, although built as a library, is unfortunately unsatisfactory in many respects and has fast become inadequate for the users which are continuing to increase. Branch libraries in the provinces are also inadequately housed (often in one small room of the municipal offices) although every effort is being made to provide proper buildings throughout the country. There is a programme under the current Seven-year National Plan to open six new libraries each year. However, only three have been build so far, and the future looks uncertain due to problems with determining design requirements and providing funds. 


\section{(a) Design of the new central library}

22. The President of the Republic has donated a 28,500 square metre plot of land on which to build a new library. The Ministry of Information and Culture intends that the building complex shall house not only a library but an exhibition and lecture hall, a theatre and small rooms for recitals, etc. These latter requirements have not been specified in detail so that it is not yet possible to determine how best the various purposes for the building can be integrated.

23. The library has initially been specified as needing to hold two million books and various administrative sections. Since the site is in an area which is expected to develop rapidly into the new residential part of Kabul, it was not possible to predict just what size of population there would be in the catchment area served by the library. At the same time, due to the overall lack of library facilifes, users tend to travel further than usually expected in Western countries.

24. It became clear after discussions that much information was still needed for a realistic evaluation and estimate of the new building design. Since the library staff has had little experience of gathering and using statistical information about the library service and its users, considerable difficulties have arisen over the specifications for the new building.

25. Initial calculations established that the estimate of two million books would take over 20 years to achieve at a minimum expenditure of four million Afs. equivalent a year. This did not allow for the purchase of books from Western countries, which would require a still higher expenditure. A more realistic estimate suggested that a 30 year span could realize a sufficient acquisition rate. However, much more needed to be known about the objectives of such a collection.

26. At the present time there is a serious shortage of works in the main languages and there seems no immediate prospect of a large publishing programme to relieve the situation. In the absence of any significant increase in this range of publishing, it is hard to see just how the library will obtain such a large collection of books in these languages. A more serious aspect, however, is the lack of information about user needs. Very little is known, statistically, as to the subjects most in demand, the failure rate at the shelves and the need for multiple copies. Without such data, designing a new library must be a matter of guesswork. In view of the unique opportunity afforded by the gift of land, it is essential that the design be based properly on adequate data and carefully evolved objectives.

27. Whilst there may be no staff with expertise in data collection, it should be possible at least, with minimum help from an expert, to collect and use such statistics as are available. For instance, it is estimated that Kabul has over half a million population; there are 25 State high schools in the city with an average of 3,000 students and a library in each; that the central public library has over 14,000 registered borrowers of which about 40 per cent are girls. Such data would make possible extrapolations of a sufficient time scale to allow the formulation of a workable design specification for the new building.

28. On the matter of objectives, it should be noted that no decisions have been made yet regarding extensions to the library services. These might include the supply of microforms and readers for them, photographing facilities, private study rooms (carrels), provision of record and tape playing facilities. Such extras will depend largely on the view which the Government takes of the likely cost in relations to expected benefits, and the expected availability of these other media. 
(b) Design of branch libraries

29. A set of designs exist for a branch library. It is hoped that each year new buildings will be erected in the provinces, mostly in the capitals. The cost of the library as designed would be about one and a half million Afghanis at present prices.

30. Discussions revealed that, as with the new central library proposals, these designs had been undertaken by the architects of the Ministry of Public Works who were given very little significant data from the libraries to work on. The outcome has been a less satisfactory design than could have been achieved with good professional advice.

31. After consultations with a qualified architect contacted through UNDP, the following points were established concerning the present design for branch libraries (see Appendix 2):

1. Partition walls as shown cannot be removed at all since they support the roof. Movable partitions should be used.

2. The windows are unsuitable for the climate generally. Indirect lighting at roof level is perfectly feasible: tinted glass should be used when windows face the sun. Glass areas should run in vertical strips.

3. The foundations as designed would not support a second storey.

4. The design of the gulley where roof and walls meet outside should not be at right angles but sloped inwards at a $45^{\circ}$ angle. This ensures all snow melting when the sun strikes the roof.

5. A more modest structural design would reduce cost per square metre, thus permitting larger libraries for the same cost.

Recommendations

32. There is urgent need for an expert in library design to advise on both the central and branch library plans. In the first instance three weeks should suffice. But it should be emphasized that the adviser would need to be well versed in the collation and use of library and other relevant statistics needed to determine optimum designs for these libraries.

33. The Afghan authorities have been urged to adopt basic standard design for all branch libraries. This aids in the costing of future programmes and simplifies both building specifications and furnishings.

\subsection{Stock}

(a) Content

\section{(i) Books}

34. At the time of the mission it was estimated that the public library service had 168,000 volumes, of which some 58,000 were located in the 32 branch libraries throughout the 26 provinces, and 75,000 volumes in the four Kabul city libraries. These four libraries comprise a central, a nearby branch, a junior library and the joint archives/manuscripts library. A further 35,000 volumes which are also the responsibility of the public library service, have been supplied to 
libraries in prisons, industry, military establishments, etc. Besides books, the library collects the national newspapers and journals. In the case of the latter, however, great reliance is placed on donations, since there is little money available for continued subscriptions to journals published abroad. Of the 200 or so titles, only some 50, mostly published locally, were received regularly. Other forms of publication are not collected because demand concentrates on books, and because present resources do not allow it.

35. While the old branch libraries keep their stock together, in many cases wholely on closed access, the central library in Kabul and the new branch libraries separate the stock into loan and reference sections. In the case of the central library, the loan collection contains 35,000 volumes of which about half are in languages not read by most borrowers. For this reason only the used half has been catalogued. This includes works in Persian, Pashto, Dari, Arabic, English and Turkish. The unused part of the collection consists of works in German, French, Urdu, Japanese and Russian. Most of this material was acquired through unsolicited donations. While this loan collection covers all subjects, approximately 90 per cent are novels. The non-fiction covers mainly sociology, folklore, psychology and philosophy. In the case of the sciences there are a few works in biology, chemistry and mathematics.

36. The reference sections comprise one covering works on Afghanistan in any language, a general reading room collection, mostly for high school students, containing works in Persian and Pashto, and a foreign literature collection containing works in English, French, German, etc.

37. The whole of the book stock, depending for much of its material on donations from any source but especially the Asia Foundation, the British Council and private citizens, displays a most unsatisfactory randomness of content. As stated above, nearly half the loan stock remains unused due either to the language of the work or equally to its age. Various administrative restrictions prevent wholesale weeding and disposal of unwanted material which would provide much needed space and lessen the problems of those looking after this stock. Although the matter of language has already been mentioned, it might be useful to note here that most readers can manage Pashto, Dari and Persian (Farsi). According to the school attended, they may also manage either English, German, Russian or French. As might be expected, however, those wishing to study in the sciences or social sciences usually have to read English language material. Unfortunately, at the moment the library service is unable to match this situation with a suitable stock.

\section{(ii) Journals}

38. The collection, kept in one small room, contains few complete runs, and donations have proved an unreliable system for acquisition. Many titles were represented by no more than sample copies. However, the dearth of journal collections in the country has persuaded the library of the need to keep anything received. This policy has resulted in a fragmented and out of date stock covering all subjects and in many languages. Rationalization of the stock is unlikely until money is available to permit subscription regularly to useful journals.

39. While some donated journals were bound prior to receipt, only the newspapers and some selected journals are regularly bound; the remainder are kept loose. Unfortunately, storage boxes of the type often found in European libraries are not available. This makes for considerable difficulties in keeping the collection tidy and in a state of easy access. Fortunately the librarian in charge of the journals section has a very good knowledge of the stock and the location of individual titles. 


\section{(b) Acquisitions}

40. The main national sources of books received by the public library is the Ministry of Information and Culture and the Ministry of Education. The latter, besides publishing all textbooks and literary works used by schools and higher education establishments, has a large output of both fiction and non-fiction made available to the public at cost price. Some works are automatically supplied to the public library which receives 30 copies of each title, free of charge. The other Ministry also has a publishing programme from which the library derives 100 copies of each publication. In other cases the library receives only two copies under the legal deposit system and must purchase others if required. All the ministries are expected to supply the library in similar manner since they all use the Governmentowned printing presses.

41. The relatively small private sector in publishing is also required by law to supply two copies of each title issued, but there is no way of enforcing this, it seems.

42. Besides unsolicited donations, a number of publications are obtained on an exchange basis. It is estimated that some 2,500 volumes are received this way each year, and involve no expenditure.

43. Manuscripts are being acquired gradually but continuously. Once each week half a dozen scholars assemble at the central public library to which people bring any items they have for sale. Each work is examined and evaluated. Those deemed worth acquiring are bid for and, when possible, a price agreed upon. Paradoxically the relatively small sums available for purchasing rare works may help to keep the prices low. Under present legislation, it is illegal to take out of the country any old article belonging to the country without clearance from the authorities, usually the National Museum.

44. Acquisition of material currently published abroad has proved to be the most unsatisfactory area. It appears that money is not available for overseas purchases so that this source yields a very small amount of the total intake to the public library. In addition to the limitation on such purchases, there is the lack of bibliographies covering the output abroad. In line with the general situation for periodicals, subscription to foreign bibliographies is not considered possible at this time. What selection is done, depends on the free receipt of foreign publishers' catalogues and announcement literature. It is also common practice for the bookshops to make lists of receipts, which are submitted to likely purchasers including the libraries.

45. The process of ordering is disturbingly protracted. All items for purchase suggested by staff or readers have to be listed, discussed and then submitted to the ministry for approval. Before the orders may be placed, requests for tender have to be placed in the local newspapers. The supplier quoting the lowest bid will normally get the order. Orders and receipts of items are for both the central public library and all the branches in the provinces.

\section{(c) Cataloguing}

46. The chief cataloguer attended the University of Aligarh library school for six months. He has trained others as assistants. There are eight staff, none of whom have any formal library training. 
47. Since 1969 when the department was formally set up, some 35,000 titles have been catalogued. Currently, publications are received and dealt with daily, totalling some 3,700 each year. Works are usually in Persian, Pashto, Urdu, Arabic or English. Works in other languages like French, German, Japanese, Russian do not get catalogued and some 40,000 titles are held which fall into this category.

48. Cataloguing is done in accordance with the old A.L.A. code and the 15th edition of the Dewey Decimal Classification. With the approval of the Iranian Library Association, certain parts of the classification scheme have been expanded by a group of public librarians. These extensions cover Persian literature and the geography of Afghanistan.

49. The cataloguing department maintains four separate catalogues at the central library - one each for the reading room, the English language material, the Afghanistan collection and the loans collection. These are all located in the hallway at the ground floor entrance. Catalogues have author and title arranged in one alphabetical sequence and a classified sequence arranged by Dewey having only one entry per title. There is no verbal subject index to the classified section. This latter is considered unnecessary since a member of the cataloguing staff is usually available to advise readers on finding relevant works under the proper class numbers.

50. Besides maintairing the central library catalogues, all branches are provided with a title card for works supplied to them. Unfortunately the need for catalogue cards will soon become a major problem. Ten years ago, Unesco presented the library with 200,000 cards. These are now down to 50,000 and can be expected to last no more than two years at the current rate of consumption. At the moment such cards are not available from sources inside the country. However, it is possible to buy large pieces of white card which could be cut into $56-5^{\prime \prime} \times 3^{\prime \prime}$ cards. Such a measure is only satisfactory when done with a proper guillotine to ensure absolute accuracy. Cards which differ in height even by a millimetre cause considerable inconvenience to users of the catalogues.

51. Other deficiencies in facilities were also noted. Despite the frequent need to produce 35 duplicate entries for the same book, there is no card duplicating system. Each card is therefore typed and checked. Similarly there is no book spine labelling device so that paper and transparent sticky tape are used for this. Date labels and book cards for use with the charging system are also not easily obtained. It should be stressed that cards, labels and pockets can be made to order but the cost could not be met from the present budget levels. To obtain 10,000 book cards, pockets and date labels would cost an estimated 21,000 Afghanis. For this reason the introduction of the Browne charging system has still not been effected.

52. Catalogue maintenance is a continuing problem and is a permanent drain on resources. In the first instance the catalogue drawers are quite unsuitable for the use made of them and the contents. Partly filled drawers do not have satisfactory supports which can be fixed anywhere along the length of the drawer. Consequently many drawers aisplay cards leaning acutely forward or backward. The rods to anchor the cards cannot be locked in, so readers often pull them out thereby endangering the cards. Due to the nuisance caused by cards being removed or full drawers dropped in this way, the ends of the rods have been bent to prevent their removal. However, this makes amendment and updating a much longer job, since rods have to be straightened to effect removal and later bent back again. Quite obviously such practices need to be stopped as soon as possible.

53. In the case of guide cards, the need is for tough fibre cards, having a raised tag for the display covered on both sides with a clear plastic protector. Unfortunately, these are not available in the country. As a consequence, due to heavy and 
often inexpert use, guide cards in the catalogue last only a matter of months before having to be replaced.

54. The cards themselves suffer considerably from rough handling and defacing caused by dirt and rubbing. This gives rise to an extra work load in that the catalogue drawers have to be continually checked for the condition of their contents and up to 20 per cent of entries produced afresh during the year.

55. A further aggravation to the chief cataloguer is the customary transfer of junior staff from one civil service sector to another. Such a practice discourages interest in training such people or in their applying themselves to learning new skills. The loss of someone who has responded well to such training is very detrimental to the service.

56. One satisfactory aspect of the cataloguing is that books received are dealt with the same day. Those for the branches are passed, after processing, to the administration section of the library. From there they are sent by post and reach their destination within a week.

57. Branch librarians, most of whom are untrained, are brought into the centre for two months' training in library practice in general as well as in cataloguing.

\section{Comments}

58. It is clear that without appropriate equipment the system is inefficient. However, it remains effective due to the number of staff available and the small number of items received per year. Yet typing out the same entry some 38 times, and checking each one, or replacing worn entries bespeaks a wastage which, even with a large pool of labour, seems unrealistic. Despite the adequacy of current methods, progress can only be achieved by deliberate improvement in efficiency, thereby permitting attention and energy to be given to other equally important aspects of the library service.

\section{Recommendations}

59. At least two staff members should be sent abroad for full professional training in cataloguing and classification.

60. Requisite stationary, book cards, pockets, date labels and readers cards to permit the introduction of the Browne charging system as soon as possible, should be obtained.

61. Copies of the new Anglo-American cataloguing rules and the 18th edition of Dewey should be obtained for the public library.

62. A card duplicating machine to permit typing a master and running off copies as required, should be obtained.

63. A spine labelling stylus or other such device is needed.

64. New catalogue drawers with screw-in rods, sliding screw locking card supports and tough guide cards, should be obtained as a matter of urgency.

65. A way should be found of ensuring the continued supply of catalogue cards. Consideration should be given to the provision of a guillotine with accurate guides and clamps to produce precisely cut cards. 


\subsection{Provision}

(a) Reading rooms

66. One of the most encouraging aspects of the central public library is the large number of high school students making use of the reading rooms and their book stocks. At the height of the school terms, queues form of students waiting to get into the overcrowded library. Even in the small provincial libraries, there were often to be seen small rooms filled with students working at projects requiring use of books from the shelves. However, little is done to promote library use or in particular to encourage adult readers. The library naturally feels disinclined to attempt campaigns which might give rise to any increase in demand for services already overstretched. The library is open every day from 8.00 a.m. until 7.30 p.m.

67. Taking into account the space available, the reading rooms offer a generous amount of seating, the large main reading room can seat some 100 people. However, the tables approximately two metres $\mathrm{x}$ one metre appeared too large for the needs of those sitting at them since there was much unused space on the centres of them. Use of narrower tables might increase seating capacity. It should be said that often students will be found standing among the bookshelves reading rather than waste time by waiting for somewhere to sit down. In the other reading rooms seating was rather cramped and again insufficient for the constant flow of users. However, no real improvement seems possible until larger rooms can be provided.

68. Whilst lighting by day and night seemed adequate, the temperature conditions left much to be desired. There is a fan in each room but these are not very effective where many people are gathered. Air movement alone is not enough to reduce the temperature during the summer months. It was not possible to vet the heating, but comment suggested that the system was not very efficient during the severe winters. Much of the trouble lies in the nature of the building itself and the lack of thermal insulation.

69. Staff are permanently stationed in each reading room. The librarian (senior) in charge is liable for the cost of any losses in his section, which encourages watchfulness rather than helpfulness. Staff do however provide readers with what help they can. This seemed to be an aspect of the service to which more attention might be given. Few of the librarians are fully trained and therefore would benefit from more instruction on ways of assisting readers, the use of information resources and search methods.

\section{(b) Loans}

70. The "circulation" department is run by a director plus two other staff. The department, which is located on the ground floor, operates on closed access and is open from 8 a.m. to $5 \mathrm{p.m}$. each day except Thursday and Friday when it closes at $4 \mathrm{p} . \mathrm{m}$. The stock holds some 35,000 volumes in all languages, though only about 50 per cent are entered in the loans collection catalogue. Readers consult this catalogue to note the details of books required. The request is written on a card which is passed through a hatchway. Only one book is loaned out at a time.

71. At the time of this mission there were 14,000 registered library members, and it is estimated that 40 per cent are girls, which is considered to reflect the ratio of males to females in the schools. Between 1,000 and 3,000 items are out on loan for a maximum of two weeks at any one time. 
72. Unfortunately the inadequacies of the stock mean that of the 300 to 500 people who regularly borrow books, and another 2,500 who borrow occasionally, many do not obtain what they want. No reservation system is operated. A feature of the loan system is that each item has to be signed out and back. While in stock, the librarian is liable for the cost of the book should it be lost. Once signed out, the reader takes on the liability. This has meant a laborious procedure whereby details of each item are entered in a ledger and signatures obtained. Until. this system is abandoned, it will be impossible to introduce the Browne charging method whereby readers have tickets in which the book card of each item being loaned out can be inserted and filed. Such a charging system would provide a very desirable improvement in the speed of processing loan transactions.

73. Like other parts of the library, the loan stock, which is arranged by Dewey Class numbers, contains much that is unused and unusable. Withdrawal procedure demands that all unwanted books must be listed and that list submitted for approval before the books may be burnt up. It is understood that this can take much time and is felt to be an uneconomic exercise in terms of effort. However, the fact remains that the loan stock could be drastically reduced without detriment to the service and at the same time lighten the burden of responsibility and administration on the librarian in charge.

\section{(c) Facilities}

74. The library is clearly discernible from the street due to the large sign on the side of the building. On entering, all cases have to be deposited. The hall contains display boards on which are pinned all the pages of the current major daily newspapers. Judging by the numbers of people who visited the library during the day to read them, this is a popular and valuable service.

75. To join the public library the reader must be able to read and write, and have a permanent address. References from the schonl or other acceptable body, have to be provided together with two forms on which relevant details have to be entered plus a passport size photograph and signature of the reader. Once countersigned by the Head of the library service or his deputy and after payment of 20.00 (twenty) Afghanis, membership is granted and is renewable annually.

76. The catalogues are all located in the hall, one for the general collection, one for the Afghanistan collection, one for English language material, and one

for the loan collection located outside the lending hatchway. A large notice on the wall explains the layout of the library, behaviour required and gives very brief instructions on how to use the catalogues. To consult these, readers tend, to remove the drawers to the tables ranged along the walls. Unfortunately, some drawers are dropped and cards are often ripped out to be taken to a librarian as evidence of what is required. A cataloguer is normally on hand in the hall to help readers find what they want and discourage the improper use of the catalogue.

77. The loan stock and the periodicals room are on the ground floor, the Afghanistan section and offices on the first floor, and the other collections on the second floor. This means that readers needing the general reading rooms, after consulting the catalogues, proceed directly to the second floor. Observation showed that the traffic flow was untroubled and smooth up the one stairway between flloors. No provision is made for the handicapped, but this is not a problem which organizations are expected or able, to tackle yet. 
78. Under the stairs, in a very confined space where one cannot stand up straight

is the bindery. One man is exclusively engaged in repairing book covers, and encasing those without them. Other than scissors and glue there was no equipment.

79. All those responsible for a library collection were located in the same room as the books. This allowed giving maximum security to stock whilst being readily available to readers. Adequate desks and chairs seem to be provided.

80. Some other staff - cataloguing, acquisition of foreign materials, planning and administration - have overcrowded surroundings in which to work. Equipment seemed adequate though there is no photocopying service. The building needs thorough redecorating. While there are lavatories for staff and readers, unfortunately these were not in good condition. The many physical problems which are evident throughout the building underline the recognized need for a much larger purpose-built library. In the meantime, due to the pressures on space, a building in the centre of the public park opposite the library, has been requisitioned as a branch. Although unsuitable in many respects, some rooms in this single floor building have been opened to the public as reading rooms having tables, chairs and a reference stock of some 5,000 volumes. The remainder of the building, when certain alterations are complete and staff available, will also be taken over. This branch offers the same services as obtained in the central library reading rooms.

81. The inside of the children's library was not seen during the mission, but the outside of the building was inspected. While it was centrally placed, access to it was certainly unsuitable for young children who would have to negotiate a considerable traffic flow without any control aids. It is understood that this library will be moved to a more suitable location. As with the central library, this children's branch is very popular. It is a matter of regret on the part of the President of the library service, that present resources do not permit the provision of a number of such libraries in different parts of the city.

82. The manuscripts and archives libraries, discussed in another section of this report, are housed in a large room in the building of the Ministry of Information and Culture. The libraries are shortly to be moved to a building which has been altered specially for the purpose in accordance with recommendations of a previous Unesco adviser.

$\underline{\text { Comment }}$

83. The signs are of a thriving service, hampered by inadequate stock, insufficient and inappropriate accommodation and some inefficient practices. Yet it should be put on record that despite these limitations the library was achieving many of its goals.

\section{Recommendations}

84. Plans for the new central library and further city and provincial libraries should be proceeded with as far as possible.

85. Professional advice about the design, layout and equipping of the new central library and standard provincial libraries should be obtained at once from architects familiar with library buildings and from library professionals with design experience.

86. Unusable stock should be disposed of and the procedure for this simplified. 
87. The stock liability requirement should cease at once.

88. Air conditioners should be installed in all reading rooms.

89. A proper bindery should be set up and at least one member of staff adequately trained abroad.

90. Smaller tables and a different seating arrangement might increase capacity and make better use of the space available.

\subsection{Management}

(a) Staff

91. All library staff are civil servants on fixed salaries, according to grade, averaging Afs. 2,500.00 per month (equivalent to U.S. $\$ 53.00$ approximately). Senior staff are selected by the librarian, while junior staff are allocated according to the dispersal pattern for each intake of government workers. Transfers between one administrative arm and another within the ministries can be frequent and sometimes are arranged at short notice.

92. Workers accepted for civil service posts must have attained high school grades. A small proportion (percentage not known) are graduates from Kabul University. Since degree subjects do not necessarily dictate the type of job to which workers are allotted, the library often has to accept people who are both without library training or experience and without any particular interest in this type of work.

93. Training is effected in the library by having new staff work alongside experienced members of staff and by sending people on courses held in the city of Kabul or abroad. After two years of active library service and some formal training, employees can be graded as professionals. Others are graded as unskilled and tend to show low motivation. The matter of training and how improvements might be made in this sphere are discussed in a separate section of this report. It is certainly evident that some of the problems which beset the library service stem from the use of staff who have little interest in librarianship as a career. In fact there is need at this stage for people who exhibit a zeal associated more with a vocation rather than just a career. At the management level there is an urgent need for fully trained professionals capable of instructing, organizing and directing the staff under them.

\section{(b) Administration}

94. At no level is there an opportunity to learn about management principles and techniques. Concomitantly there is scant opportunity to exercise such knowledge. Low salaries and a pool of labour allows the inefficiencies engendered by the lack of training to be offset by a higher number of employees. However, this is not to say that all sectors are overmanned. Some parts of the library service rely heavily on those willing to do overtime to cover all the shifts necessary in the reader service areas.

95. A particularly hampering aspect of the administration is the seeming reluctance to delegate responsibility. The consequence of this situation is that heads of sectors have to sign and often compose letters or memoranda going outside the department. All work is personally though perhaps not closely supervised by the manager. For those in top positions the work load is very heavy indeed. Preoccupation with the minutiae of day-to-day administrative matters, prevents needed attention being given to planning and discussions about the future of the service. In short, the present system does not allow those in responsible posts sufficient time to think. 
96. The effective supervision of staff tends to be undermined by the inertia which the unwilling can resort to, knowing that they cannot be discharged and that a transfer is always possible. While some of the staff work inordinately hard, others prove relatively unproductive.

97. Until a new system of recruitment is instituted, and more incentives provided, little improvement can be expected. A further unsatisfactory aspect of staff control is that since the librarian of each sector in the library is personally liable for every item, he naturally insists on adopting whatever measures or routines he considers necessary to protect the stock in his care. This effectively blocks staff mobility between jobs and sectors.

98. The liability aspect also creates some inefficiencies. Whenever a new librarian is appointed he naturally is required to sign for the items in stock. However, before doing this he requires reassurance about completeness. Thus the administrative sector has to check the entire stock recording afresh details of every item present. Perhaps when stocks contain millions of volumes, the practice will be abandoned. A similar exercise is perpetrated whenever a stocktaking is ordered. Elaborate multipart stationery is used to enable provincial librarians to sign for items sent to them through the post. Efficient methods of stock control are out the the question so long as the liability requirement remains in force.

99. The reluctance of managers to allocate tasks may have serious repercussions on the progress of the library service. Its expansion is a pressing matter requiring statistical data supporting carefully structured plans. These last must compete with demands from other quarters on the always inadequate resources. Priorities can be awarded when plans clearly show the purpose and benefits, initial and recurring costs and the time-scale of intended progress. To produce such plans, detailed statistics of library activity and other relevant data like population concentration, etc. need compiling and interpreting. The head of the library service needs staff capable of undertaking this. There is a need for the whole attitude to staff use to be liberalized.

100. The last point under the heading of management relates to succession. There is no attempt to groom people so that they are fitted for promotion to middle management jobs. There is no defined career structure. Staff have difficulty in seeing a progressive future for themselves. This is a contributing factor to what seems the frequent lack of motivation among staff.

\section{(c) Finance}

101. Each year budgets are submitted to the Minister of Information and Culture. Usually there are two such budgets. One relates to annual recurring costs like salaries, book fund, etc. The other relates to special purchases which are not expected to recur. Such extra items might include equipment, furniture, buildings or alterations thereto, or new staff.

102. Budgets, like some other submissions, may be discussed by the various heads of other sections within the ministries. This keeps every section informed and prevents inordinate imbalances of expenditure among them. Also special requests have to be defended against the comment round the table. The Minister also vets the submissions which in their final stage are passed to the Ministry of Planning and the Ministry of Finance. They are eventually presented to the Prime Minister's office. Final sanction comes from the President of the Republic. 
103. Obviously all such negotiations take time. Unfortunately lists of books wanted for purchase are included in the submissions and so take months to reach the shelves. While the library does have a small float for contingencies, there is not enough to permit purchasing books directly from sellers. Government practice requires that all purchases have to be put out to tender so that the lowest price can be obtained. Unfortunately, this sometimes leads to the acquisition of less suitable goods.

104. All budgets cover costs to be incurred by the library service in the city of Kabul as well as those it runs in the provinces. As could be expected, monies voted for the whole service are never enough to meet the aspirations of the planners. Some money is contributed by local authorities (municipal and provincial) but this does not seem to alleviate the shortage of money to meet the increasing demand for library services throughout the country.

\section{Comment}

105. Management as an art and a science has not yet reached the library. However, good management can provide a better climate of work and generate interest even among tine apathetic. Foundations of good management practice need laying down now if large scale mistakes are to be excluded from the accelerating development programme for the library service. Certainly the first area to tackle appears to be that of delegation of responsibility.

\section{Recommendations}

106. Promising staff should be enabled to gain management training abroad.

107. A much more frequent and broader programme of training should be provided for staff likely to benefit. Those trained abroad should be required to pass on their training in formal courses for others.

108. A research team to back up the planning and to initiate new ideas and procedures should be set up comprising three senior staff with others co-opted as and when necessary.

109. Discussion groups, to exchange comments and ideas should be held regularly for senior and junior staff together. 


\section{NATIONAL LIBRARIES}

110. There has now been established a National Archives Library and a Manuscripts Library which are housed together in a large room in the Ministry of Information and culture building. The stock is kept in display cases and steel cupboards ranged round the walls. The archives comprise over 1,000 documents, while there are estimated to be over 2,000 manuscript volumes. These latter are being added to steadily with the purchase each week of selected items from among those offered by private citizens to the library for purchase. The archives are expected eventually to include all papers from the ministries and provincial offices. However, no arrangements have been made yet to transfer these documents to the national library.

111. The two libraries are to continue together in a reconstructed building which is now finished except for the air conditioning. This building incorporates many special features in accordance with the detailed recommendations of a Unesco adviser, Mr. A. I. Diamond, made in his report submitted in 1974. Special facilities have been made to allow the display of illuminated manuscripts, storage in controlled fireproof conditions, provision of photographic copyring services, $(1)$ and the proper care of the valuable materials.

112. The Manuscripts Library is run by a staff of ten headed by a journalism graduate from Kabul University who attended an eight month course in Hawaii University on the care and management of archive material. It is evident, however, that more people will have to be trained for archives and that equipment essential for preservation work will have to be obtained. Since no attempt had been made to index documents already in the archive collection, it was not possible to judge the adequacy of those who will be doing this work. But it seems likely that at least two staff would need particular training in this. It is understood that the library expects to obtain scholarships enabling students to attend relevant courses in India.

113. The manuscripts collection has a staff of four including a professor and headed by an historian. Considerable difficulties have been experienced over the preservation of these works. Due to lack of any suitable aids, many volumes have had to be labelled using paper and sticky transparent tape. Some manuscripts when bought were found to have sticky tape used to mend torn pages. From those inspected, it would appear that generally speaking the paper and illuminations are unharmed but bindings have suffered considerably from the unsuitable environmental conditions and previous poor handling whilst in private ownership.

114. Items on show in the glass cases which were presented to the library, have explanatory labels accompanying each. The contents of these labels testify to the care, scholarship and hardwork of the present librarian. However, if the present collection is to be properly catalogued there is a need for at least two staff to attend courses. Again, as with the archives, equipment and facilities will be needed.

115. While a number of recommendations for the reconstruction of the building have been carried out, it was not clear whether the equipment specified in the Diamond report could be obtained. So far large sums of money have been spent on the structure and it may be that money for equipment will not be available for a while. Should this be the case, then both collections will benefit minimally from the new quarters.

(1) For details see Appendix 3 
116. The present arrangement places these collections under the authority of the President of the Public Library Service. Since ultimate responsibility lies with the Ministry of Information and Culture, this arrangement seems satisfactory enough. What is more, there is an undoubted advantage in having resources and funds channelled through the public library. This enables allocation to be decided on the basis of needs arising month by month. Any fragmentation of resources or duplication of administrative effort must be detrimental. In this connexion it should be noted that the large sums required for the archives building might be considered to be taking an inordinate proportion of funds which might equally have been used for library services which some might consider more urgent. Had the money been used to build, equip and stock a new central public library, many of the troubles discussed in other parts of this report might have been alleviated.

117. There are no plans yet to set up a national library to collect all the publications of the country or those of neighbouring countries. Nor are there any proposals for the establishment of a comprehensive collection of national and foreign periodicals. Certainly discussions suggest doubt about the availability of sufficient funds for any such ventures.

118. At the present stage of library development in the country, attention could be better focussed on creating two centres of excellence - one at Kabul University and the other at the central public library. If funds can be found then the university could concentrate on the maintenance of a comprehensive stock covering science and technology and the social sciences, while the public library could cover the arts and humanities. This would lessen the burden on each library while permitting them to concentrate the use of their resources.

\section{Conclusion}

119. Rationalization of the entire library resources as between the public and university sectors would provide considerable benefits. It might be helpful to consider the establishment of centres of excellence. More people inviolved with manuscripts and archives need proper training.

\section{$\underline{\text { Recommendations }}$}

120. The librarian and one other in the Manuscripts Library should be sent abroad for training particularly in historical and descriptive bibliography, and so too should others for the Archives Library.

121. Advice should be obtained about procedures on site for the care and maintenance of rare or precious material.

122. A reappraisal should be made of the requirements for the archives building as to equipment, to determine realistic priorities in relation to funds available.

123. Centres of excellence should be established in Kabul for books and periodicals, based in the public library and the university.

124. Advice and further training is needed in order to set up proper photographic copying services. 


\section{UNIVERSITY LIBRARIES}

(a) Kabul

125. This relatively new and extremely well run library was opened in 1964. The stock of 98,000 volumes is divided up among the loan collection, reference, Afghan section and bound journals. There is also a full collection of dissertations. Some 15,000 books are being catalogued by the three staff allocated to this job. Both the loan collection and bound journals are on closed access. Total staff number 50, including three professionals trained in the United States or Iran. The library uses the Library of Congress classification scheme. It is intended to maintain a union catalogue covering the contents of the central and faculty libraries. Although the library does have a budget, acquisitions depend mostly on donation and exchange. In this connexion, the problem of journal subscriptions is particularly acute since there is not nearly enough money to guarantee maintenance of runs, most of which date from 1962 .

126. The opening hours are from $8 \mathrm{a} . \mathrm{m}$. to $7.30 \mathrm{p} . \mathrm{m}$. on six days each week during term time. The total student population is about 8,700 with 2,000 new students each year. The study areas provide some 200 seats. The academic staff number more than 900 .

127. There are seven faculties which have and support their own libraries. A visit to the Faculty of Veterinary Science provided information on how such libraries fare. A small but modern room with good shelving, periodicals rack and about 12 seats for students, contained some 500 volumes. This collection had been taken over from the Faculty of Education, so that many books were quite inappropriate. With few exceptions the material was ten years old. Very few journals could be obtained on subscription so that exchange and membership of professional bodies by the staff are the main sources. The librarian is a science graduate without any library training.

128. The faculty has over 300 students on the five-year course which began in 1973.

All teaching is in English, so material in this language is needed urgently. FAO funds are used but only through the two approved suppliers in New York and Copenhagen with concomitant delays. No research or higher degree work is done yet.

129. As with the main library, material from abroad is difficult to obtain because of currency exchange restrictions. The small amounts provided for this purpose are unlikely to be extended. It was clear from comments received that there is a pressing need for the translation of basic works into Dari, Pashto and Persian.

130. It was understood that with the exception of the medical faculty, the faculties had poor library services.

(b) Nangahar University (not visited)

131. This university has but one faculty - that of medicine. Whilst it does have a corporate identity, the Kabul university library is responsible for its library budget and for the acquisitions and cataloguing of its books.

132. With the present shortage of trained staff and resources in general, this centralization appears to be a most satisfactory way of organizing that library service. 
133. Again, while the library there is relatively good, much more money and staff is needed. This is particularly pressing for Nangahar since the medical faculty has a very high reputation to maintain.

\section{Conclusions}

134. For the main university in the country it must be seen as absolutely essential that the library service is supported to ensure adequate stock and staff. The teaching programme must surely suffer without a library to provide a continuous supply of up-to-date literature. It seems that the solution to the present problems lies largely in the money supply. The library is well organized but would benefit also from more trained staff.

135. Untypically in this institution, the librarian is not custodian of the library stock and is not personally liable for book losses. When the library was opened, loan stock was on open access, but after a year it was enclosed.

\section{$\underline{\text { Recommendations }}$}

136. Very high priority should be given to the provision of a wide range of journals. Only in this way can the academic staff keep up to date.

137. The provision of many more trained staff is particularly important here. With a university library of this size and importance it must be considered essential that a streamlined service including full information services be provided. The faculty have no other sources on which to draw. The library has therefore the duty to keep all staff alerted about relevant new literature as soon as possible after its publication, and then make this literature available as speedily as possible.

138. A photocopying service for students and staff should be installed immediately. For ease of maintenance and cheapness of paper it is recommended that an electrostatic dry copier be chosen.

139. Upgrading of the faculty libraries, especially that of engineering, is also urgently needed. LThe medical faculty however, has an excellent library though with the usual dearth of journals. $/$ 


\section{TEACHER-TRAINING COLLEGES.}

140. Besides the two colleges in Kabul, there are nine in the provinces. Most of them are for primary school teachers. Total number of students is approximately 4,500 and teachers 400. About one-third of the students are "in-service", the rest are designated "pre-service" coming direct from school or university.

141. All the colleges have libraries which are run by one full-time untrained librarian and assistants. Most have high school or some university training, though only one was a graduate. The book stocks owe much to donations from the Asia Foundation and the British Council. The smallest library had 3,000 books and the largest over 7,000. There is the usual problem of language spread. Due to donations, English language material predominates with that for Dari next. Pashto is on the whole poorly represented. A sample of stocks in five colleges is shown in the accompanying table (Figure 3 ).

\section{Figure 3}

\section{Sample of language spread among library book stocks of 5 teacher-training colleges in Afghanistan}

\begin{tabular}{|c|c|c|c|c|c|c|c|c|c|}
\hline College & \multicolumn{2}{|c|}{ Eashto } & \multicolumn{2}{|c|}{ Dari } & \multicolumn{2}{|c|}{ English } & \multicolumn{2}{|c|}{ Other } & Total \\
\hline & & $\%$ & & $\%$ & & $\%$ & & $\%$ & \\
\hline 1 & 50 & 0.6 & 3,460 & 66.5 & 1,710 & 32.9 & - & - & 5,200 \\
\hline 2 & 50 & 1.4 & 1,450 & 40.3 & 2,000 & 55.6 & 100 & 2.7 & 3,600 \\
\hline 3 & 75 & 1.9 & 925 & 24.1 & 2,835 & 73.6 & 15 & 0.4 & 3,850 \\
\hline 4 & 150 & 3.0 & 1,100 & 21.8 & $2,4^{85}$ & 49.2 & 1,310 & 26.0 & 5,045 \\
\hline 5 & 1,250 & 16.7 & 2,100 & 28.1 & 4,050 & 54.2 & 70 & 1.0 & 7,470 \\
\hline
\end{tabular}

Source: Private communication

142. Just as with the schools, the libraries in the colleges are not used enough, nor is there any attempt made to use library materials in teaching. A further aggravation of the situation arises from the change in the curriculum decreed in March 1974 by the Ministry of Education which is responsible for all these colleges. Many basic textbooks are not yet available and this places a further strain on the poor resources of most libraries.

143. A considerable amount of work is being done by Unesco experts to teach the use of visual aids and to make better use of library resources. Unfortunately their work is hampered by the usual practice of requiring the librarian to be personally liable for every book in the library. This means that libraries are opened only when the librarian himself is there. There is considerable resistance to a allowing users free access to the library stock. 


\section{Conclusion}

144. Quite plainly a most important aspect of teacher training should be the use of the library. Without ideal library conditions it is hard to see how teachers are to learn about the potentialities of a library. Were they to have access to proper facilities, not only would their teaching methods benefit but they would understand better how to raise the standards in the schools in which they finally teach.

Recommendations

145. The appointment of a library adviser within the Ministry of Education would underline the importance of library services and their use in these colleges. Such a person could assist in training people to man the libraries properly, coordinate the supply of books, advise on organization and assist development. He could also act as liaison officer to the minister vis-à-vis library matters in the colleges. It would be sensible if such a person were also to have similar responsibilities with respect to school libraries.

146. Better library facilities, especially stock, should be obtained as soon as possible.

147. Considerable efforts should be made to integrate the library service with the teacher-training curriculum.

148. At least one person in each library should be given adequate training. 


\section{SCHOOL LIBRARIES}

\section{(a) General}

149. All schools are the responsibility of the Ministry of Education. They are categorized into village, primary, intermediate, high schools and vocational. There are nearly 3,500 village and primary schools with approximately one million students. Most are without libraries of any kind. There are over 500 middle schools and nearly 200 high schools. Over 100 are considered to have libraries - the book collection must exceed 500 volumes to be designated a library.

150. The Ministry of Education intends to install libraries in 50 more schools each year. Of the three high schools visited in Kabul it was clear that standards varied considerably. Discussions with other experts in touch with schools elsewhere confirmed that the libraries seen in Kabul were representative of those throughout the country.

151. High schools, where libraries are most necessary just now, tend to have a student population of between 3,000 to 4,000. Senior students are taught during the morning sessions of four hours and juniors in the afternoons. Most members of the staff are from the Teacher-Training Colleges. However, some schools are beginning to adopt a policy of graduate recruitment from Kabul University. Classes are typically large with 50 to 60 students each. Due to the size of classes and lack of facilities, teachers are unable to depart much from traditional teaching methods.

\section{(b) Stock}

152. Library requirement and use is, therefore, less than might be hoped. Book stocks varied between 1,000 to 3,500 volumes. A few national newspapers and magazines are also usually obtained regularly. Condition of the books and journals depended much on the recency of donations from the British Council, the Asia Foundation and other bodies. The date of works varied from the early 1900s to 1974 . Unfortunately, donated material does not always match the needs and content of the school curriculum. One school was especially well stocked because great emphasis was placed on the use of English. The school therefore accepted many English books for use by teachers and students. Subject coverage varied considerably and without much regard to the subjects being taught. In many cases there were serious omissions, whilst in others there were insufficient copies to support even moderate project work. Textbooks are not provided in the library, since the Ministry of Education supplies every student with course books each year. Unfortunately, these textbooks are replaced only every three years so that students may receive books which have already been used by two previous students. Such books are often in poor condition and incomplete. As with other libraries the problem of language creates considerable difficulties when deciding on acquisitions. The language used for teaching depends on the district in which the school is located. In Kabul the language used is Dari whilst other districts use Pashto. At the same time many books of use to the school may be in Farsi (Persian). Second or third languages taught in schools vary between English, German, French and Russian. Books from any of these languages may be included in the library stock. However, their use depends considerably on the capability of the teachers in the languages concerned, since standards among staff vary considerably from one school to another. 
153. While donations can form a significant part of the acquisition source, the Ministry does allow every school a small amount of money each year for book purchases from the Ministry itself or from booksellers. The high schools tend to have sums ranging from 10,000 to 20,000 Afghanis. While this sum may be regarded as inadequate, nevertheless a careful selection policy applied each year could result in the build up of a good working library. Teachers are expected to provide the information about the books they require. The head of the school, after discussions with the staff, finalizes a list, within the budget, for submission to the Ministry once or twice each year. No help is provided to inform teachers about books which are recently published. The person in charge of the library is not given any responsibility for book selection except in connexion with the subject which he may teach.

\section{(c) Management}

154. Most times the libraries are looked after by one of the teachers. Full-time staft teach 24 hours each week, while those with duties such as librarian may be required to teach only six hours per week. As would be expected, the organization of the library depended as much on personal enthusiasm as on competence. Some libraries are tidy but do very little to encourage use. Others besides being obviously efficiently run also provided an atmosphere of busy interest with wall displays of maps, pictures and diagrams.

155. For convenience, the stock is arranged first by language and then by subject. All use the Dewey Decimal Classification system. Interestingly one school had their own copy of the 16th edition of Dewey, whilst another had made a complete table of the first 1,000 divisions of Dewey from which all books were classified. It was general practice to obtain catalogue cards, for all books held, from the Franklin Service. The Franklin Service was run from 1961 to 1972 . It was responsible for the printing of books and their distribution with catalogue cards to all the high schools. In 1973 the Ministry of Education took over the printing press and the card service ceased. This American firm now operates from Tehran. Three cards are used for each book to be indexed by class, author and title. The two latter are filed in one sequence. There are separate catalogues for material in the romance languages since these cannot be interfiled with Persian and the like. Quite apart from the difference in character sets the former runs from left to right while the latter is the reverse. No subject index is supplied since the librarian is expected to guide children to the class numbers required to find relevant material.

156. Whilst the books themselves were adequately marked, self guides are not provided, and catalogues lack sequence guides. One school attempted to provide a positive library service, by issuing a pamphlet to new students which includes a section on library use. This library also issues an examination guide listing relevant references available in the library.

157. None of those in charge of school libraries has any formal library training. However, the Director-General of library services under the Ministry of Education, besides running the Ministry library, also organizes courses for school librarians. This seems to be the only attempt to raise the quality of library service. Quite apart from the severe lack of trained librarians, there is as yet no policy decision to man school libraries with qualified people in the foreseeable future. 
(d) Use

158. While some libraries open only one or two hours each day, most are open all

day from $8 \mathrm{a.m}$. to $5 \mathrm{p.m}$. Since libraries are housed in one room, there is usually room for no more than 30 students to sit. But in the schools seen, large tables (approximately $2.5 \mathrm{~m} \times 1.2 \mathrm{~m}$ ) were provided on which to work. These took up a lot of space unlikely to be required for this purpose.

159. All students are allowed to use the library and indeed some schools are able to set small projects requiring simple research among the reference works in the library. Only about ten per cent of the students would be allowed to borrow books. In the case of girls schools this is a particularly acute matter. Families are reluctant to let their young daughters go unaccompanied to the public library, or to remain at school to work in the library beyond the set times for classes. In view of this, such schools attempt to provide loan copies of all essential material as chosen by the teachers. Some schools include in the curriculum some instruction on the use of the library and reference books. But this tends to be left until the eighth grade (high school ends at the twelfth).

160. Undoubtedly the most satisfactory material for project work tends to be in English. Since most students cannot read this, useful work with this material is restricted to the last two years or so at school. However, a sufficient and increasing number of students come from families where English is spoken, so that material in this language does get used by a small group which may increase.

161. No use is made of students to help with running the library. Some, it should be stressed, may travel a long way to and from school. Such journeys rely upon an uncertain transport system of buses, but in general little encouragement is given to students to involve themselves in library activities.

\section{Conclusions}

162. On the whole the libraries serve the schools well enough within the expenditure and facilities available. The major problem lies in the attitude of the staff generally to the value and rôle of the library. While the poor quality of the book stock discourages use, submission of lists of new books or journals wanted can take a year to be authorized, so that the waiting time between request and appearance on the shelf is very long. Often the book wanted may no longer be available. No school is allowed to have a cash float for even small purchases such as glue for posting labels.

163. Lack of sufficient books and journals, appropriate equipment and trained staff in the libraries have together prevented school libraries from becoming a significant part of the educational programme.

164. One last point should also be made. As with other libraries, the school librarian or the head of the school has to sign for every book and journal. Such a practice must deter many from allowing children of all ages and backgrounds to use the library freely.

165. The statistics below illustrate that the demand in schools and further education establishments can be expected to grow steadily. It is understood that since 1973, when Afghanistan became a republic, all sectors of education including the student population have increased more rapidly than before. It is therefore essential that the relevant library services be developed quickly. Particularly, minimum standards for school libraries should be formally drawn up, published and 
backed by official implementation and support. Failure to vitalize these library services will entail a larger and more difficult job later. Orientating children especially to library use, must be considered essential if higher studies are to be encouraged.

\section{Figure 4}

Estimates of staff and students in schools and higher education establishments of Afghanistan

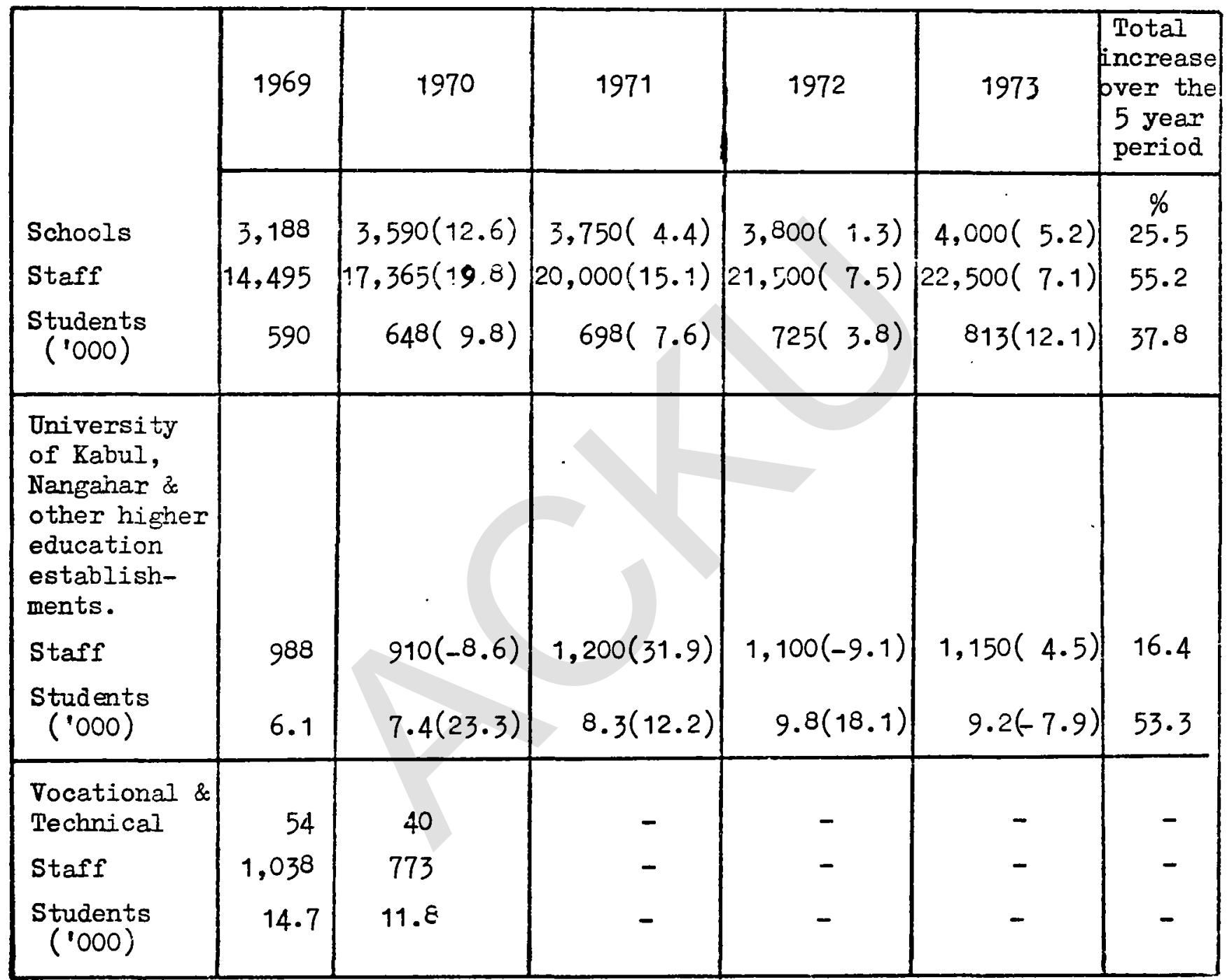

NOTE: The above estimates have been based on various statistics officially published by Afghanistan government departments.

Figures in brackets show percentage increase or decrease over the previous year. 


\section{Recommendations}

166. Stock

(a) Schools should be allowed to use their budget at any time during the year by purchasing books against Ministry credit. Since all purchases would have to be billed and items so purchased accessioned and catalogued in the library, such a method would still conform to the controls required.

(b) Subscriptions to journals should be agreed by the Ministry at the beginning of the financial year and billed direct as renewals arise.

(c) Much less reliance should be placed on donations.

(d) Books for young children should be provided.

(e) The Ministry of Education library service should provide an alerting service for schools to keep them informed of all relevant material available both from the Ministry and from neighbouring countries.

(f) Librarians should be used to provide back-up material for use in the classroom.

(g) Material, already in the libraries, which is obviously too old or quite unusable should be thrown away.

(h) At least five copies of student textbooks should be available for reference in every school library.

\section{Facilities}

(a) While larger rooms for high school libraries are needed, immediate improvement could be achieved by the use of smaller tables. This would allow an increase in seating capacity.

(b) Much better guiding as to the arrangement of the stock and use of books would help and encourage students.

168. Staffing

(a) It is to be hoped that in the future trained librarians will be placed in libraries of the high and vocational schools at least.

(b) Students should be actively encouraged to participate in the work of the library.

\section{Management}

(a) Every school library should be open all the time students are in the schools. The library stock should be assigned to the school not an individual.

(b) A new service for centralized catalogue card supply should be provided as soon as possible. 


\section{INDUSTRIAL LIBRARIES}

170. It is estimated that there are over 200 large- and medium-sized companies. However, there are many small companies also, with less than 30 people.

Cottage industries are also producing knitted and embroidered goods and the like. The accompanying table, although somewhat out of date, at least gives an indication of orders of magnitude in relation to manufacturing establishments.

\section{Figure 5}

Manufacturing establishments in Afghanistan

\begin{tabular}{|l|l|l|l|l|}
\hline & 1967 & 1968 & 1969 & 1970 \\
\cline { 2 - 5 } & 10 & 14 & 15 & 16 \\
Metals & 13 & 14 & 16 & 16 \\
Wooden materials & 10 & 10 & 12 & 12 \\
Light inaustries & 28 & 35 & 40 & 49 \\
Food stuffs & 25 & 28 & 36 & 39 \\
Other & 44 & 48 & 57 & 60 \\
\hline \multicolumn{1}{|l|}{ T O T A I } & 130 & $149(14.6)$ & $176(18.1)$ & $192(9.1)$ \\
\hline
\end{tabular}

NOTE: Figures in brackets are percentage increases over previous year.

171. The two factories visited were well organized and equipped. Quite advanced methods of manufacture were being used. Both had laboratories for testing and quality control.

172. The larger factory, manufacturing textiles, had German and Russian machinery for spinning, weaving, etc. The company employed over 5,800 people. There was a room adjoining the product exhibition hall where copies of standards were kept and which was designated the technical library. The small collection of material did not include books and journals, nor was anyone officially responsible for it. Discussions with officials and engineers at the company established that a technical library service was not considered necessary. In the light of company policy, all technical know-how is imported with the machinery from either Germany or Russia. There are no plans to institute any kind of research programme. Problems arising from faults in materials, processing or machinery are dealt with ad hoc by foreign trained national engineers on the staff.

173. The smaller company produced a very wide range of goods including steel office furniture, buses, rebuilt engines, chemical plant and heavy castings. Again there was a room set aside as the technical library. However, there were few books or journals, but it did act as the central file for all engineering drawings. The laboratories concerned themselves exclusively with quality control and shop floor problem solving. 
174. The larger factory is sited some 80 kilometres outside Kabul. Because of this, the company provides housing, a health service and a small library for the workers. This did have a librarian, though untrained. The stock of some 1,500 books varied greatly as to language, subject and age. The library opens one hour a day after work finishes.

\section{Conclusions}

175. The two companies visited were untypically large and more technologically advanced than most others. Since even with these two, officials do not see the need for an information service for their engineers, nor for a research and development programme, it is clear that provision of industrial libraries is assigned a low priority. For many firms the standard and type of production would not seem yet to require technical information services.

\section{Recommendations}

176. Factory workers' libraries need attention urgently, especially for the children. Such provision should not be the responsibility of the firms concerned. It is recommended that the public library service be given funds to provide a library service in factories employing not less than 1,000 people. At this time such a figure will apply to less than 20 companies. However, as funds become available it could be expected that the eligibility bar would be lowered to embrace more establishments. The service should consist of a supply of books supervised by a librarian. The book stock would be changed by the public library once every four months. Stock removed could then be used as a fresh supply in another factory and so on.

177. It does seem that senior engineers were preoccupied with day to day problems. They were unconvinced about the need to see any published material beyond that received from the professional bodies abroad to which some of them belonged. Unless an information service of high calibre is set up outside the companies, there seems little prospect of arousing interest in new methods. Such a service could be computer based but essentially it would have to be run by a qualified engineer will full training in technical documentation placed in the Ministry of Mines and Industry. Such a service would have to be directed at individual engineers and backed up by a properly related document collection and copying service. Any references supplied as part of a regular technical information service must have been evaluated and summarized in informative abstracts. Lists of titles and origins would not be of much use.

178. As an appendix it should be added that companies do maintain connexions with organizations abroad to obtain advice and relevant new technology. One company maintained close liaison with research organizations in the Philippines, Turkey, Thailand, Italy and Czechoslovakia. In some instances teams are sent abroad to evaluate or learn new techniques. The absence of research in the country does not mean that no cognizance is taken of developments.

179. Interestingly in one case, the Director, who is an engineer, acted as the "technological gatekeeper" disseminating relevant information received to appropriate people on the staff. 
7. TRAINING LIBRARIANS AND THE ROLE OF THE AFGHAN LIBRARY ASSOCIATION

180. Most of those working in libraries have no training at all but some training programmes do exist. The situation is as follows:

181. A. Within the country:

1. Ministry of Education - regular courses, mainly for school librarians, are run under the guidance of the Director-General of Library Services. The courses deal mainly with indexing and library operation. Those attending are from schools and colleges.

2. Public libraries - the central library runs courses for its own staff and those of the provinces.

3. British Council - sends specialists to give courses on various aspects of library work. These courses are for invited participants.

4. Asia Foundation - sends specialists to offer courses for those in schools and colleges.

182. B. Outside the country:

Scholarships are offered by the following countries: Iran, India, United States of America, United Kingdom, Germany and Russia. All those at present holding degrees in library science received them from United States establishments.

183. There is no professional course in the country and no certificated training courses for library technicians. Those sent abroad usually attend specialists courses such as archive management or indexing but these are rather randomly offered and allocated. It seems that those attending such courses do not in turn pass on the knowledge by conducting similar courses within Afghanistan.

184. If librarianship is to become a profession in the country then the foundations for it need laying now. Certainly the handful of qualified people cannot successfully raise standards without the establishment of formal library education. As the country develops, libraries become more important to support the educational and technical advances. Such libraries will not be effective without adequately trained staff.

\section{The Afghanistan Association}

185. Despite hopes for the Association on its founding in 1971, there has been no meeting since the first and no activity. At present there is no focal point for professional views to be synthesized or voiced, nor is there any exchange of views among the senior librarians. It could also be beneficial to establish international contact through the International Federation of Library Associations. This organization has established a Working Group on Developing Countries.

186. It seems that few senior librarians are able to spare time for promoting the Association. The recommendations below emphasize the need for an active body which can speak for the profession, set standards and promote advancement in the knowledge of library science. 


\section{Recommendations}

187. Department of Library Science - it is already a matter of urgency that such a department be established at Kabul University. Initially students would graduate as Bachelors of Library Science. After ten years, higher degree courses should be available up to doctorate level.

For the first few years it would be necessary to use foreign experts to teach various parts of the course. One such expert should be recruited to run the department, organize the curriculum and teaching for at least the first two years. After five years, nationals could be expected to take over, a substantial part of the teaching having been tutored in this by the foreign experts. Besides theory and practice in the course, students should also do practical sessions in various types of libraries. Where possible they should see some libraries abroad on a two or three week tour.

188. Library assistants' course - such a course would give those not taking a degree an opportunity to obtain a proficiency qualification accredited by the Afghan Library Association. The Association could act as examining body. Initially an overseas expert would need to work with designated professionals for some six months. There would be a need for adequately structured modules with options for specializing. Those attending could be expected to be on day release for one year. Since teaching methods, development of aids and student material would have to be devised and developed, perhaps overseas experts already in Kabul could provide help.

189. Specialist courses - there is a marked need for courses in areas like statistics, library design, reference work, indexing, subject bibliography. It would greatly improve the situation if experts could be provided from abroad to teach one or two of these courses for a month each year, then many of the problems which face those responsible for running libraries or sections of them would be eased.

190. Scholarships - selected people should be sent abroad to visit libraries and to attend relevant courses running at the time. However, it must be said that this system is less fruitful when the individual is not used properly on his return. At present the knowledge gained is not systematically passed on to others. In future it would be better if conditions of acceptance include a full report which has to be published as part of the library literature for the country.

191. Library literature - there is almost a total lack of literature in librarianship. The courses suggested above will not be successful unless literature in the field is obtained. Hardly anything has been written, and certainly nothing of use for courses. Unless something can be done about this, a rôle which the Association could accept, then few of the recommendations above can be implemented satisfactorily.

\section{Incentives}

192. Unless some incentive is provided, staff will not see any advantage in attending courses. It must be axiomatic that graduates in library science obtain a higher salary than those without and similarly that those with certificates be better paid than those without. 


\section{BROADCASTING}

193. At the present time broadcasting in Afghanistan is wholly the responsibility of Radio Afghanistan from studios in Kabul from which all programmes are sent out, having been previously recorded. The only live broadcasting is that by news casters and programme announcers. Due to the terrain, reception in many areas is poor. Transmissions from surrounding areas tend to intrude on those from Kabul when listeners are sited more than a few hundred kilometres from the city transmitter. Broadcasting runs from 6 a.m. to 8 a.m., 12 p.m. to 1 p.m. and 4 p.m. to 11 p.m. The first is put out on one channel, the others on three. Frequencies are in the medium- and short-wave bands assisted by some relay stations. It is hoped in 1977 to establish 13 stations to cover the whole country. Initially they will act as local relay stations but eventually might put out local material. The overseas service goes out between $2 \mathrm{p} . \mathrm{m}$. and $7 \mathrm{p} . \mathrm{m}$. every day.

194. The programmes concentrate on serious subjects and music. From the point of view of library services a number of aspects are pertinent. It is estimated that there are one million receivers and that probably between six to ten listen to each one, giving an audience of between six to ten million. Since no audience research is aone these figures are not verifiable. It is known that transistor radios are increasingly popular because of their cheapness. The table below shows estimates of receivers imported into the country

\section{Figure 6}

Estimate of the number of radios and radio composites imported into Afghanistan

\begin{tabular}{|l|c|c|c|}
\hline & 1971 & 1972 & 1973 \\
\cline { 2 - 4 } Radios & 22,800 & $22,500(-1.3)$ & $22,000(-2.3)$ \\
Radio taperecords & 17,000 & $17,500(2.4)$ & $22,000(25.7)$ \\
Radiograms & 9,000 & $9,800(8.9)$ & $8,100(-21.0)$ \\
\multicolumn{1}{|c|}{ T O T L } & 48,800 & $49,800(2.0)$ & $52,100(4.4)$ \\
\hline
\end{tabular}

NOTE: Figures in parenthesis show percentage increase or decrease. Estimates based on officially published sources.

195. Radio Afghanistan runs a variety of educational programmes. Language courses in English, French, German, Russian, Pashto and Urdu are run continuously. However, there are no facilities for publishing booklets for listeners to use when following courses. Supply of some kind of aids to learning a language could fall on the public library which is not often in a position to provide them.

196. There is a childrens' programme for one hour each day but the consultant was unable to find out how much attention was paid to books and reading. There is storytelling, though little is said about the source in literature. Nor it seems are such programmes intended to encourage children to read particular books. 
197. Books are reviewed in the. "Golden Mirror" programme and discussed by scholars as well as professors from the university. There is also a general knowledge quiz programme each week separately for boys and girls from high schools and the university. About 600 attend paying 10-15 Afghanis each. Books are presented as prizes.

198. Each day a Rural Agriculture programme is put out for 50 minutes covering problems, family matters and health education. Again there is no publishing programme to back this up but Radio Afghanistan does publish the monthly "Pashtoon Jugh" containing talks, stories, poetry, criticisms and interviews. These programmes are devised by the relevant ministries. Broadcasting liaison staff advise on structure, production, etc. and their engineers undertake the recording and editing.

199. Plans are now underway for the start of television within the next three years. Japanese advisers are directing the establishment of studios and transmission network. It is understood that although the cameras will be for colour most of the receivers would be monochrome and miniature in order to keep down the cost. Schools will be among the first to be given sets for receiving special broadcasts in the classroom. No decision has yet been taken regarding the provision of handbooks to accompany these broadcasts for either teachers or students.

\section{Conclusions}

200. It seems that literature back-up for programmes is not yet considered important. Instead the public library, with already over-stretched resources, has to make material available which relates to the programmes.

201. Some time is given to discussing books, but again until the public library can cope, further publicity for the books, which would stimulate reader interest, could prove embarrasing for the library.

\section{Recommendations}

202. Radio Afghanistan linked as it is with the Ministry of Education should jointly with them produce handbooks for listeners for courses in languages and other appropriate areas.

203. Recordings of talks should be made available on audio-tape cassettes for use in schools throughout the country. 


\section{(a) Printing}

204. Most printing is done by Government owned presses. Both the Ministry of Education and the Ministry of Information and Culture (MIC) own large presses in Kabul. The latter is also responsible for 14 provincial presses. The Government Printing Press (GPP) owned by MIC has 12 lino-type machines and two mono-type machines. Letterpress work is done on old but sound Heidelberg cylinder machines (also used by the provincial presses). Large runs are done on high speed presses but only capable of two colour work. Since all photographic originals are in black and white, all coloured reproductions are produced by hand painting four plates. Resulting pictures were of high quality considering the conditions under which this work is done. All the technical processes seemed to be adequately supported by equipment and specially fitted rooms.

205. Besides forms, stationery, official cards and the like, the press produces some three million volumes each year. It is responsible for printing, collating and binding all books and periodicals. The GPP also prints daily the Jamhouriat in Dari and Pashto (1973-), Anis in both languages (1927-), Hawad in Pashto (1949-), and the Kabul Times in English (1962-) and some 26 magazines and society journals. The GPP, however, is not responsible for the distribution network for any of its production. Circulation for the daily newspapers is estimated at less than 10,000 each.

206. As might be expected the press has difficulty in obtaining trained skilled technicians. Some are sent to Germany, the United States or the United Kingdom, but not enough to fully employ all the equipment available in the press. The management is hoping to change over to photo-typesetting and web-offset within the next five years. However, lack of computer facilities and personnel may make this estimate over-optimistic.

207. The Ministry of Education has its own press which up to 1973 was jointly managed with the Franklin Publishing Co. Last year it produced nearly two million copies of textbooks. A further two million were produced for the Ministry by the Government Printing Press. It is hoped to extend the facilities to cope with an output of nine million textbooks a year.

208. There are some private presses which undertake short runs of letterpress publishers. work, and also produce a few thousand copies of books for commercial

209. Government owned (under MIC) provincial presses are responsible for producing local newspapers and journals and undertaking other work on a commercial basis.

(b) Publishing

210. Newspapers and magazines are mostly in the hands of the ministries. Books, however, may be published in various ways. The Ministry of Education has almost exclusive control over the production of books for schools and colleges. Besides the standard textbooks, supplied free to every child, there is also a steady production of advanced texts. Some are for the use of teachers in schools others are directed at university students. The Ministry of Education has a Department of Compilation and Translation which is responsible for writing or commissioning textbooks. Since Afghanistan is not a signatory to the Berne Convention, books from 
abroad are freely translated for distribution or sale. Great efforts are presently being made to meet the demand arising from the new curriculum, particularly for the teacher-training colleges.

211. The small number of private publishers deal in novels and poetry monthly. Since the private market is small, runs do not usually go beyond 1,000 copies. Authors are either paid a fixed sum or get ten per cent royalties.

(c) Bookselling

212. It has been estimated that there are nearly 200 bookshops in Kabul. Most are small and stock less than 2,000 volumes. The book business is supplemented by the sale of cards and stationery. The trade is divided into general and rare book dealers.

213. It is understood that sellers operate on a narrow profit margin. Afghans it seems, though generally unused to buying books, do provide a steady market. Prices per volume vary from 50 to 300 Afghanis. Exceptionally, imported art books and the like are available, but often wait years for a buyer. Private publishers aim at 100 to 200 Afghanis. All Ministry of Education publications are sold at cost price. The Ministry also remainders quantities of older material once it has been superseded.

214. All the general bookshops have a surprisingly wide range of material as to content and language. Persian, Pashto, Dari, English, French, German and Italian titles are commonly encountered, the first three are usually in the low price range. European literature tends to be extremely expensive and can attract mark ups to 400 per cent on the stated price. There is no net book agreement nor indeed a publishers' or a booksellers' association. The bookshops therefore try to establish a regular clientele and hope for a good supplementary trade from tourists. Some are able to sell to the libraries.

215. One aspect of the book business is that there are no organized bibliographic services, nor even publishers catalogues in the country. Booksellers are expected to inform their customers of new material. Some are able to duplicate lists for circulating to libraries. As explained under the public library service section, purchasing through Government departments can be a lengthy procedure so booksellers may have to wait months before a booklist realizes sales. 


\section{COMPUTING FACILITIES}

216. The main computer in the country at the moment is housed in the basement of the Intercontinental Hotel, this being the one air-conditioned building in Kabul. The machine is run by Afghanistan Business Machines Co. (ABM) a company which is jointly owned by Ariana Airlines, Afghan Textile Co., the National Bank, etc. Since the major shareholders are themselves Government majority owned, ABM is effectively a public corporation.

217. The configuration of the machine, an IBM $360 / 30$ is:

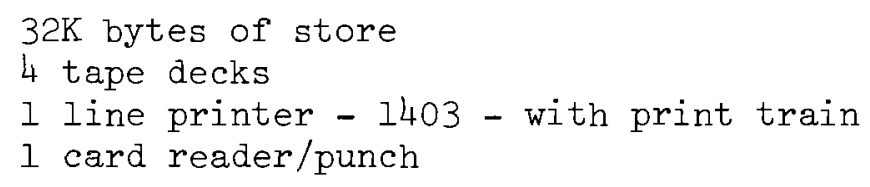

218. There is also a small IBM 1103 with one disc kept as reserve and used for meteorological work.

(a) Use

219. Up till now use of the computer has been limited to Ariana Airlines, the Bank and the Ministry of Planning. Average number of computer hours per year is 120. It is hoped that this will be raised to 600 within the next five years. Plans are being made to offer time to organizations in Pakistan on a commerical basis. The University of Kabul has also been offered 25 hours a year free of charge but it seems they are unable to take advantage of this yet.

220. No libraries use the computer. It is most unlikely that even in the new central library, using the computer for library housekeeping operations would be feasible or advantageous.

221. Due to the ample amount of spare time, the Director of the unit is quite willing to set up a Selective Dissemination of Information (SDI) service based on any tape service which seemed appropriate. Such would be Compendex or AGRIS. However, with the present facilities, retrospective searching would not be feasible since cumulated tapes could take too long for acceptable costs per search.

222. The machine is run with four operators and eight programmers. All have been trained abroad. Most of the work is in COBOL, with occasional use of FORTRAN, since the computer is used exclusively for data processing.

223. Since the Kabul University has not yet established a computing department or courses in computers, there is still no prospect of obtaining nationally trained staff.

\section{(b) Data preparation}

224. The unit uses punched cards exclusively. There are nine machines. Women punch operators are trained by the data processing supervisor. Error rates can be as high as ten per cent but in view of the work load this does not cause serious problems. 
225. Two card sorters are used to presort cards before passing through for processing. It seems that with the present software this method is faster than tape sorting.

\section{(c) Services}

226. Only a few engineers and scientists trained abroad have knowledge of computers. In consequence the offer of computing services to an organization inevitably entails full systems evaluation and design. The Director of ABM encounters many difficulties when trying to explain the procedures and benefits of computer use. The programming staff too have great problems of liaison with users or potential users. Even large organizations are apprehensive about surrendering their systems, such as accounting, to an outside body.

227. Libraries would suffer from the same difficulty but with added complications. Not only is there no one in the library field with knowledge of computers, but there is only a handful of foreign trained librarians familiar with the systems organization necessary before computerization. It can be assumed that use of computers is most unlikely for library purposes until there are appropriately trained librarians.

228. ABM expects that within the next five years (1976-1981) the configuration will be increased by at least one disc unit. Also on-line service could be expected. However, while teletypes could be used in the present PTT system, use of visual display units would have to await installation of the microwave system. This latter could enable transmission speeds of 2,400 Bauds with minimum corruption. Online services could be used for small cumulated files of highly selective references extracted from information service tapes. Also in the next decade it is to be hoped that a library science course established probably at the university would use such facilities for teaching information retrieval methods. 


\section{INFORMATION SYSTEMS (NATIS)}

229. It is not known exactly how many journals are produced in the country but most are either of the magazine category or related to historical aspects. None could be considered as the basis of a national data base for information systems in any major subject field. Neither are there people sufficiently trained to undertake documentalists' work.

230. There are some relatively small programmes of scientific research (i.e. development work). This is due to lack of the right people, lack of facilities and money. Most technology is imported. Until the need is seen for development of vigorous research and development programmes as a national policy, there is unlikely to be much activity. However the Ministry of Agriculture does undertake development work.

231. As a consequence of what has been said above, and taking into account the existence of only one data processing machine in the country, it can be assumed that participation in international information systems is unlikely within the next five years. At this stage pressingly urgent matters require all the Government funds available. It is likely that there is no large volume of literature which could be added to establish a data bases, while very few in the country could yet make use of a complex information network.

232. Equally serious is the absence of a national scientific literature collection which would be a prerequisite for any significant activity in this area.

\section{Recommendation}

233. Despite what has been said there could be something to gain from the use of such a service as Compendex to alert relevant engineers in their fields

about useful material but the information scientist concerned would have to evaluate all items retrieved and organize the supply of originals. 
12. GENERAL CONCLUSIONS

234. Despite the unstinting efforts of trained and untrained librarians throughout the country, the library services still falls short of requirements.

235. Undoubtedly the greatest single factor is the lack of money, particularly the difficulty in obtaining any publications from abroad. Because of this shortage of money and in particular foreign exchange, it is imperative that the library movement progress in the most efficient way. To this end is made the final recommendation:

236. It is strongly recommended that a national library adviser be appointed by the Government. Under his direction would be an adviser for schools and teaching establishments, and the public libraries services. This appointment should promote co-ordination and best use of limited resources, and the establishment of continued training programmes. 
SUMMARY OF RECOMMENDATIONS

1. PUBLIC LIBRARY

1.1 Buildings - (paragraphs 33, 34 and 85, 86)

(a) Advice of an architect experienced in library design is needed urgently for the central and branches. Plans need proceeding with at once.

(b) Professional help is needed with layout and equipping of new libraries.

1.2 Cataloguing - (paragraphs 60-66)

(a) A copy of the 18th Dewey Decimal Classification should be obtained.

(b) A card duplicating machine is needed.

(c) A book spine labelling device should be obtained.

(d) A new more suitable set of catalogue drawers is wanted with reinforced guide cards.

(e) Catalogue card supplies need to be guaranteed or the supply of a guillotine with which to make them.

1.3 Facilities - (paragraphs 87-91)

(a) Stock should be weeded out and unusable items disposed of.

(b) Stock liability requirement should cease.

(c) Air conditioners should be provided in reading rooms.

(d) A bindery, properly equipped and staffed should be set up.

(e) Smaller tables should be used in the reading rooms.

1.4 Management - (paragraphs 107-110)

(a) A staff training programme should be set up so that some go abroad to learn modern management methods and then teach others.

(b) A research team of about three staff should be set up to collect planning information.

(c) Discussion groups should be held regularly among senior and junior staff. 
2. NATIONAL LIBRARIES - (paragraphs 121-125)

(a) Two staff from the Manuscripts Library should be sent abroad for training.

(b) Further advice should be sought on the care of manuscripts.

(c) There should be a reappraisal of the priorities for equipping the new building.

(d) Centres of excellence should be established in Kabul for books and journals.

3. UNIVERSITY LIBRARIES - (paragraphs 137-140)

(a) More journals should be provided.

(b) More trained staff are urgently needed.

(c) A photocopying service (dry copies) should be made available at once.

(d) Faculty libraries should be upgraded as a matter of urgency.

4. TEACHER-TRAINING COLLEGES - (paragraphs 146-149)

(a) A library adviser in the Ministry of Education (perhaps the person now responsible for school libraries) should be appointed.

(b) Libraries in all these colleges need upgrading.

(c) At least one trained librarian should be in each college.

5. SCHOOL LIBRARIES - (paragraph 167-170)

(a) The upgrading and installation of school libraries should be accelerated.

(b) There should be greater liaison between school librarians and teachers.

(c) Only properly trained librarians should be used to run the libraries with assistants if necessary.

(d) More textbooks are needed.

(e) Libraries should be open all day in term time.

(f) A catalogue card service should be reintroduced. 
6. INDUSTRIAL LIBRARIES - (paragraphs 177-180)

(a) Factory workers' libraries should be the responsibility of the public library. All firms with over 1,000 employees initially should be entitled to a regular book delivery service.

(b) A trial information service using COMPENDEX, the computer based engineering index service, should be set up for twelve months in the first instance.

7. TRAINING LIBRARIANS - (paragraphs 188-293)

(a) A Department of Library Science should be installed at the university and initially run in part by experts from abroad.

(b) A library assistants course should also be instituted.

(c) The Afghan Library Association should become the examining body.

(d) Scholarships to send people on visits abroad should be sought.

(e) Efforts should be started to provide library science literature in the national languages.

8. BROADCASTING - (paragraphs 203, 204)

(a) Radio Afghanistan should be encouraged to publish handbooks for courses on the radio.

(b) Recordings for schools should be made available.

(c) There should be close liaison with the publishing activities of the Ministry of Education.

9. COMPUTER SERVICES - (paragraph 234)

The computer should be used for starting an SDI service. 
APPENDIX 1

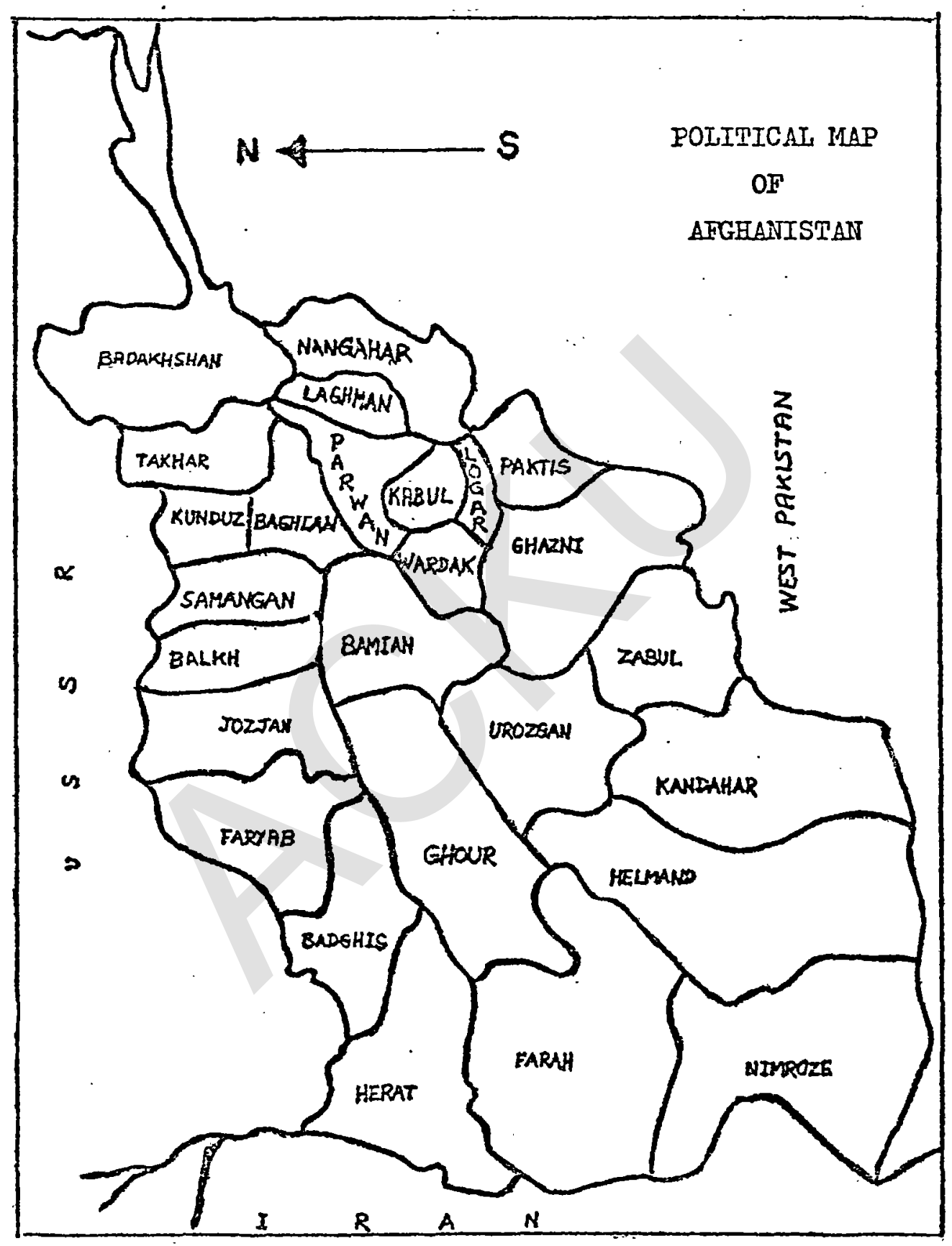


APPENDIX 2

Details of branch library designs

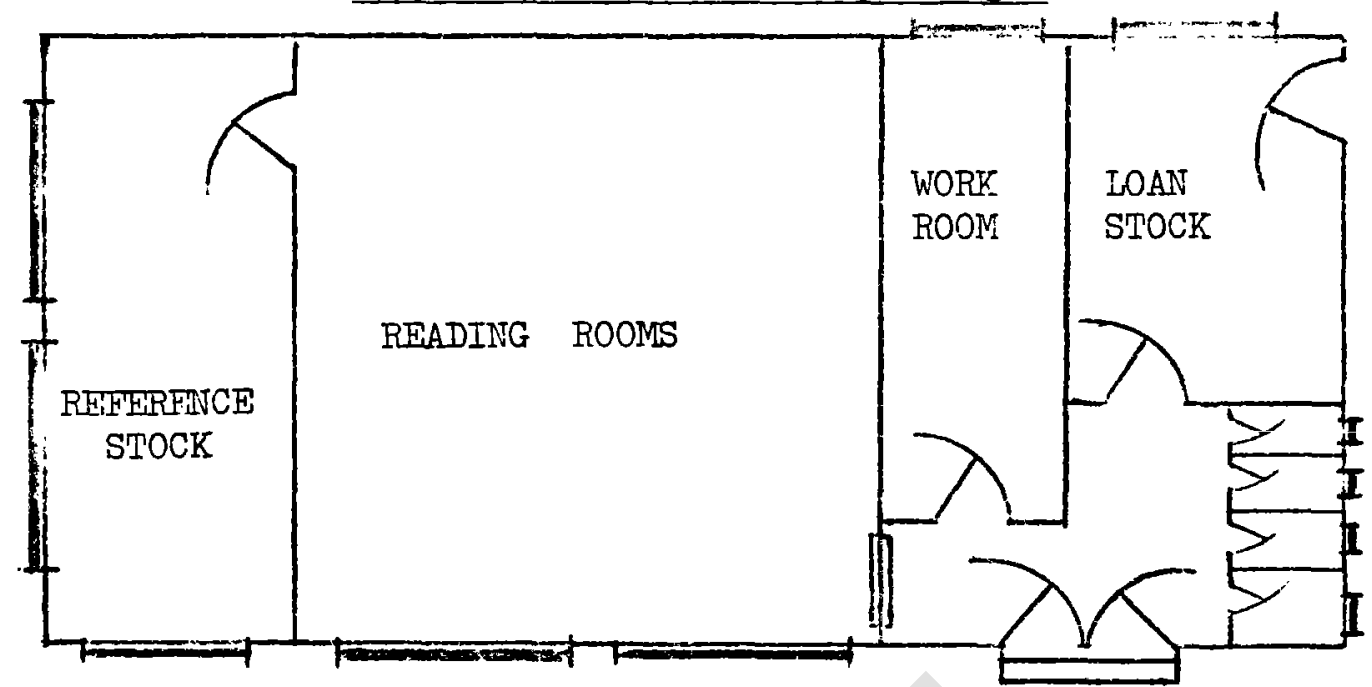

(a) Interior - showing fixed interior walls. To allow alteration of the areas, removable partitioning should be used.

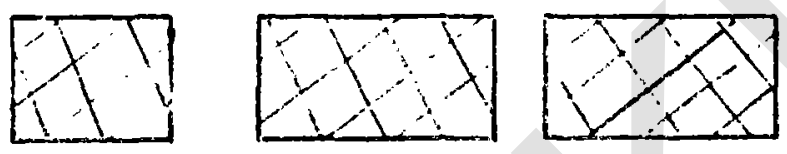

(b) Front elevation - ABOVE - as designed.
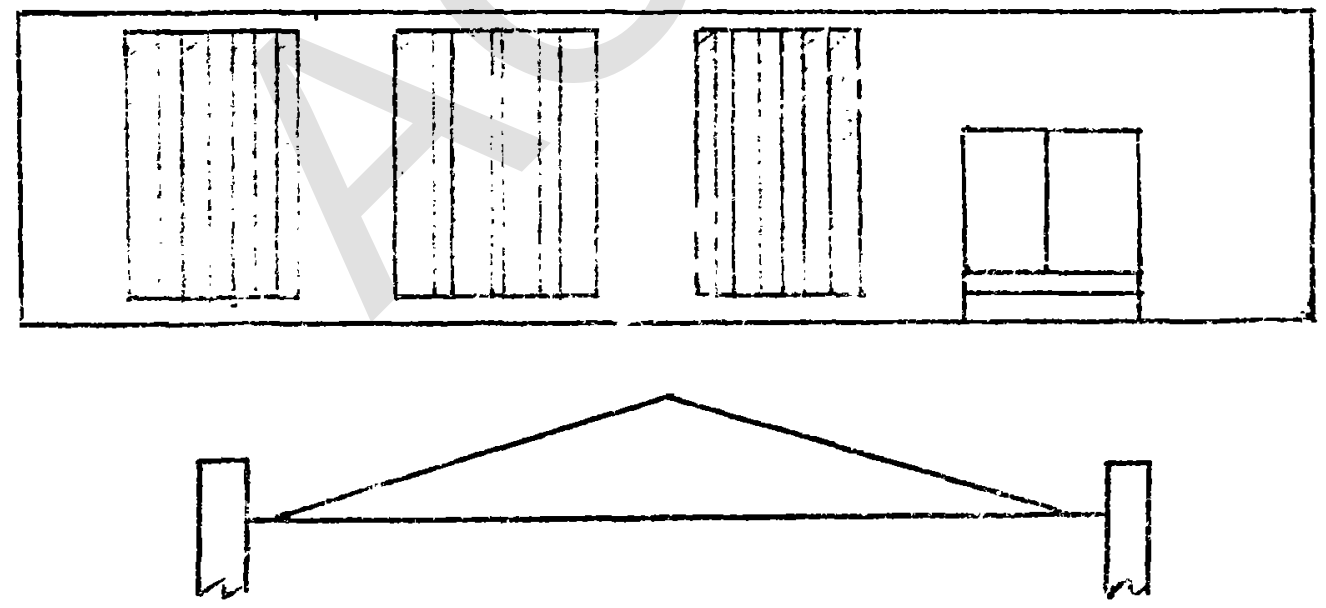

(c) Roof profile - ABOVE - as designed.

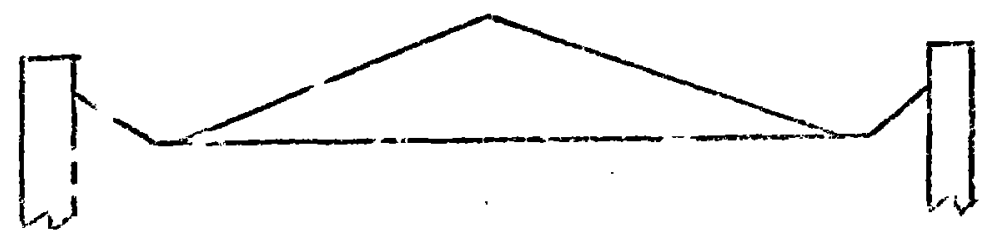

NOTE: Diagrams are not drawn to scale. 
APPENDIX 3

Details of photographic equipment at the National Archives Library

(All purchased 12 years ago)

A. One camera - KONTOPHOTO with $4.5 / 75 \mathrm{~mm}$ lense

Intended for copying from manuscripts

B. Two microfilm projectors - VC Micro Methods Ltd.

Projects slides and rollfilm

C. One epidiascope - Aldis $35 \mathrm{~cm}$. 


\section{APPENDIX 4}

REFERENCES

\section{Published in Afghanistan}

Statistical Pocket Book of Afghanistan, 1971.

Kabul: Department of Statistics, Ministry of Planning, 1972, 202 pages.

The Afghanistan Republic Annual, 1974.

Edited by A. A. Danishyar.

Kabul: Ministry of Information and Culture, 1974, 330 pages.

The Afghanistan Republic Annual, 1975.

Edited by A. A. Danishyar.

Kabul: Ministry of Information and Culture, 1975,383 pages.

\section{Other}

Diamond, A.I. Establishment of a national archives service: Afghanistan. Paris: Unesco, 1975.

Rahel, S. Cultural policy in Afghanistan.

Paris: Unesco Press, 1975, 49 pages.

Rahin, A.R. Library conditions in Afghanistan.

Unesco Course for Teachers of Librarianship.

Copenhagen, 1970.

Reid-Smith, E.R. Library development in Afghanistan.

Unesco Bull. Libr. 28 (i), Jan.-Feb. 1974, pages 17-2l.

Sharify, N. Libraries in Afghanistan in The Encyclopaedia of Librarianship, pages $111-117$. 


\section{APPENDIX 5}

SCHEDULE OF TALKS AND VISITS

\section{July 1976}

$7 \quad$ Talks with $\mathrm{Mr}$. Seddiqi and $\mathrm{Mr}$. Nayyer

Tour of the Central Public Library

8 Talks with $\mathrm{Mr}$. Seddiqi

Lecture to library staff and invited librarians from other ministries on "The Library and the User"

Talks with Mr. Haider (Chief Cataloguer)

Talks with Mr. Khazade, President of Culture

Talks with Mr. Seddiqi, President of the public libraries

Il Visit - UNDP and library

Talks with public library staff

12 Attend - rare books meeting - public library

Visit - manuscripts library. Discussions with Director and staff

Visit - Ministry of Agriculture - Department of Extension and

Development. Discussions with Mr. Pizaro

13 Visit - Kabul University Library. Discussions with Director

Visit - Kabul Polytechnic Library. Discussion with Deputy

Visit - Archives Library. Discussion with Director and staff

14 Visit - Veterinary Faculty Library (Kabul University).

Discussion with Dean

Visit - site of New Central Public Library

15 Discussions with Director of public library planning on design of new library

Lecture to invited librarians on "Indexing"

17-19 Official engagements connected with the celebrations for the founding of the Republic of Afghanistan

20 Talks on design for the new provincial libraries

Talks with librarian of Prime Ministry Library about the Afghan

Library Association

Talks with public library staff

21 Visit - Afghan Textile Co. - Gulbahar - Factory and Workers' Library. Discussions with Vice President

Visit - provincial library and press at Charikar in the Province of

Pawan and inspected the new library under construction

22 Discussions with invited group of librarians on planning and the use of statistics

Lecture - to staff on "Management"

Visits - to bookshops 
July 1976

24 Visit - Afghan Business Machines Co. (Computer Centre). Discussions with President

Visit - Radio Afghanistan. Discussions with President

25 Visit - Government Printing Press. Discussions with Technical

Vice President

Visit - Jangalac Engineering Co. Discussions with Chairman

26 Visit - Ministry of Education. Discussions with the Vice President, Ministry of Education and Culture

Visit - Noor Eye Institute and library

27 Visit - Ghazi High School. Discussions with staff

Visit - Ayasha Durrani College. Discussions with Head

Visit - Naderia Lycee. Discussions with Head

28 Talks with architects on new library designs

Talks with public library cataloguing section

Talks with public library circulation section

29 Discussions on public library catalogues

Lecture - to staff on "Librarianship as a Profession"

31 Visit - British Council Library

Talks with Mr. K.A. Ahang and Mr. A. Sultan

Talks with public library - foreign acquisitions section

August 1976

$1 \quad$ Visit - public library microfilm unit

Talks with Director of Manuscripts Library

Talks with public library - administration section

Seminar - Collation and use of library statistics

2 Talks with public library - acquisitions section

Talks with programme co-ordinator. Unesco Educational Development

Project

3 Talks with Deputy Minister of the Ministry of Information and Culture 


\section{APPENDIX 6}

\section{LIST OF PEOPLE VISITED}

The people named below were interviewed on matters directly connected with the mission. Discussions with many others, not here recorded by name, ranged over the various problems of the country and its library services.

Mr. R. A. Borthwick

Mr. A. Bjorgung

Mr. M.O. Seddiqi

Mr. A.G. Koschann

Mr. M.A. Nayyer

Mr. F.M. Khazade

Mr. S.M.S. Pizaro

Mr. M.I. Stwodah

Dr. M.R. Osman

Mr. G.M. Azimi

Mr. A. Sharifi

Mr. A.Q. Nazari

Mr. S.Y. Wassiq

Mr. A.K. Ghafoori

Mr. M.A. Saifi
Resident Representative - UNDP

Assistant Resident Representative - UNDP

President of the Afghan Public Libraries Kabul

Deputy Director-General of the Afghan Public Libraries - Kabul

Director of the Manuscripts Library (Guide and interpreter for the mission) Kabul

President of Culture at the Ministry of Information and culture

Director-General of Information and Publications of the Department of Extension and Development - Ministry of Agriculture - Kabul

General Director - Kabul University Library

Dean of the Faculty of Veterinary Science Kabul University

Vice-President - Afghan Textile Co. Gulbahar - Pawan

Librarian - Provincial Public Library

Charikar - Pawan

President - Afghan Business Machines Co. Kabul

President - Radio Afghanistan - Kabul

Technical Vice President - Government Printing Press - Kabul

President - Jangalac Engineering Co. Kabul 
Mr. H. Makmus

Mrs. Z. Maqsoudi

Mr. M.A. Miazad

Mr. J. Urguidi

Mrs. L. Mathews

Mr. K.A. Ahang

Mr. A. Sultan

Mr. M.M. Husain

Dr. A. Wahidi

Others seen informally:

Mr. J.M. Wicks

Mr. D.S. Scott

Mr. N.K. Lowe

Mr. T. Stockley
Acting Head - Ghazi College - Kabul

Head - Ayasha Durrani College - Kabul

Director - Naderia Lycee - Kabul

Previously of the Asia Foundation Library Service

Librarian - British Council - Kabul

Founder of Afghan Book Publishing Book Dealer - Kabul

Technical Documentalist - Water and Power Authority - Kabul

Educational Development Project - Unesco Ministry of Education

Deputy Minister - Ministry of Information and Culture

Unesco - Primary Teacher-Training Expert

Senior Agricultural Adviser - FAO - Kabul

Expert in Science Education - Unesco -

Kabul

Field Extension Service - FAO - Kabul 